\title{
Revisão taxonômica de Micrandra Benth. (Euphorbiaceae s.s.)
}

\author{
Paulo José de S. Souza ${ }^{1,3}$ e Ricardo de S. Secco ${ }^{2}$
}

Recebido: 6.06.2013; aceito: 21.01.2014

\begin{abstract}
Taxonomic revision of Micrandra (Euphorbiaceae s.s.)). Micrandra Benth. is a Neotropical genus with its center of diversity in the Amazonas River basin. The species are trees, rarely shrubs with unisexual, apetal flowers, 3-10 stamens, schizocarpic fruits, and seeds either with or without a caruncle. As part of a review of this genus, collections of Brazilian and foreign herbaria were consulted, including type specimens. Nine species are recognized: Micrandra elata, M. gleasoniana, M. inunatada, M. lopezii, M. minor, M. rossiana, M. siphonioides, M. sprucei and M. spruceana. Micrandra elata and M. minor are new records for Colombia, and M. spruceana for Acre and Mato Grosso States, Brazil. Two species are considered new synonyms and two new lectotypes are designated. The morphological relationships between Cunuria Baill. and Micrandra are discussed. New morphological data and ilustrations are provided for M. sprucei. An identification keys to species, geographical distribution data and comments on the species are presented.

Keywords: Amazonian flora, Crotonoideae, Cunuria, Micrandreae
\end{abstract}

RESUMO - (Revisão taxonômica de Micrandra (Euphorbiaceae s.s.)). Micrandra Benth. é um gênero neotropical com centro de diversidade na Amazônia. As espécies são árvores, raramente arbustos, com flores unissexuadas, apétalas, estames 3-10, fruto esquizocarpáceo e sementes carunculadas ou sem carúncula. Como parte de uma revisão do gênero foram analisadas amostras herborizadas, incluindo coleções-tipo, das seguintes espécies: Micrandra elata, M. gleasoniana, M. inundata, M. lopezii, M. minor, M. rossiana, M. siphonioides, M. sprucei e M. spruceana. Micradra elata e M. minor são novas ocorrências para a Colômbia, e M. spruceana para os Estados do Acre e de Mato Grosso; quatro táxons são considerados sinônimos novos e dois lectótipos são designados. As relações morfológicas entre Cunuria Baill. e Micrandra são discutidas. São acrescentados novos dados morfológicos em M. sprucei. Uma chave de identificação, ilustrações, dados de distribuição e comentários das espécies são apresentados.

Palavras-chave: Crotonoideae, Cunuria, flora amazônica, Micrandreae

\section{Introdução}

Seguindo-se APG II (2003), Euphorbiaceae sensu latu foi segregada em três famílias (Euphorbiaceae s.s., Phyllanthaceae e Picrodendraceae), sendo que o gênero Micrandra Benth. está posicionado em Euphorbiaceae sensu stricto. Esta inclui espécies com flores unissexuadas, um óvulo por lóculo do ovário, além de látex leitoso ou transparente e colorido, e sementes carunculadas na maioria dos seus representantes. De acordo com Webster (1994), o gênero pertence às Euphorbiaceae, subfamília Crotonoideae Pax, tribo Micrandreae (Müll. Arg.) Webster, juntamente com Cunuria Baill. (quatro espécies e uma variedade), Hevea Aubl. (ca. 10 espécies) e Micrandropsis W.
Rodr. (gênero monotípico), com espécies restritas à Guiana e região amazônica.

Micrandra tem como características básicas folhas com um par de glândulas basilaminar ou acropeciolar na face adaxial, indumento de tricomas simples, presença ou ausência de tufos de tricomas nas junções das nervuras principal e secundárias, flores apétalas, sendo as estaminadas com 3-10 estames, com disco basal lobado ou não, pistilódio presente ou ausente, flores pistiladas com disco anelar ou cupulado, estilete trífido ou ausente, estigma bífido, bilabiado ou bilobado, inteiro ou rotado, estaminódios presentes ou ausentes, fruto esquizocarpáceo explosivo, sementes carunculadas ou sem carúncula.

1. Parte da Dissertação de Mestrado do primeiro Autor. Programa de Pós-Graduação em Ciências Biológicas - Botânica Tropical, Universidade Federal Rural da Amazônia e Museu Paraense Emílio Goeldi, Belém, PA, Brasil

2. Museu Paraense Paraense Emílio Goeldi, Departamento de Botânica, Av. Magahães Barata 376, 66040-170 Belém, PA, Brasil

3. Autor para correspondência: pjsousabio@gmail.com 
Esse gênero esteve associado ao conceito de Cunuria, gênero proposto por Baldwin \& Schultes (1947) com base em variações de características das folhas, estípulas, flores e sementes. Apesar de Schultes (1952) ter considerado Cunuria como sinônimo de Micrandra, autores como Webster (1994) e RadcliffeSmith (2001) mantiveram Cunuria como um táxon válido.

Jablonski (1967), em um tratamento para as Euphorbiaceae da Guayana Highland, fez considerações gerais sobre as relações taxonômicas, características morfológicas e distribuição de Micrandra, fornecendo uma chave de identificação e uma lista das espécies. Berry, em Webster et al. (1999), propôs uma sinopse das sete espécies de Micrandra para a Flora da Guiana Venezuelana, sugerindo cerca de 15 espécies para o gênero. Secco (2005) tratou duas espécies (M. siphonioides Benth. e M. spruceana (Baill.) R.E. Schult. ocorrentes na flora da Reserva Ducke, Manaus.

Após uma minuciosa consulta bibliográfica, verificou-se que Micrandra não havia sido alvo de uma revisão atualizada, permanecendo os tratamentos de Baldwin \& Schultes (1947) e Schultes (1952) como os atuais, o que justifica o presente estudo. Os referidos estudos não contemplaram a grande maioria das coleções depositadas em herbários da Amazônia, que é o centro de diversidade do gênero. Além disso, praticamente todas as descrições completas de Micrandra permaneciam como Cunuria, conforme se verifica em Baldwin \& Schultes (1947). Portanto, este trabalho tem como objetivo realizar uma revisão taxonômica de Micrandra Benth., visando determinar o número de suas espécies, atualizar as identificações e descrições, assim como a distribuição geográfica e verificar a posição sistemática em relação a Cunuria, do ponto de vista morfológico. Paralelamente, visa também fornecer subsídios para atualizar as Euphorbiaceae s.s. na Lista de espécies da Flora do Brasil (Cordeiro et al. 2013).

\section{Material e métodos}

O trabalho foi baseado principalmente em material botânico depositado nos seguintes herbários, incluindo alguns tipos, cujas siglas estão de acordo com Thiers (2012): A, B, BM, CR, DAV, F, G, GH, GOET, IAC, IAN, INPA, K, M, MIRR, MG, MO, NY, P, RB, R, S, SP, TCD, U, UEC, US, VEN, W. Material adicional (referente à Micrandra siphonioides e M. minor) foi coletado na área da Embrapa Amazônia Oriental, Belém, PA. As coleções foram analisadas em estereomicroscópio, acoplado com câmara clara, tomando-se medidas de folhas, inflorescências, flores, frutos e sementes. Nas descrições adotou-se as terminologias de Lawrence (1973), Radford et al. (1974), Rizzini (1977), Webster et al. (1996), Barroso et al. (1999) e Souza \& Lorenzi (2008). Os dados sobre os locais de ocorrência, época de floração, frutificação e distribuição geográfica foram obtidos das etiquetas das exsicatas examinadas e através de observações de campo.

\section{Resultados e discussão}

Micrandra Benth., Hooker's J. Bot. Kew Gard. Misc. 6: 371.1854.

$\equiv$ Pogonophyllum Didr., Vidensk. Meddel. Dansk Naturhist. Foren. Kjobenhavn 1857: 144. 1857. Tipo: Pogonophyllum elatum Didr.

三Cunuria Baill., Adansonia 4: 287. 1864. Tipo: Cunuria spruceana Baill.

三Clusiophyllum Müll.Arg., Flora 47: 518. 1864. Tipo: Clusiophyllum sprucei Müll.Arg.

Árvores, raramente arbustos, monóicos. Ramos estriados ou não, glabros, ou esparsamente pubescentes a pubescentes. Indumento de tricomas simples. Folhas simples, alternas, peninérveas, nervação broquidódroma ou craspedódroma, membranáceas, cartáceas ou coriáceas, elípticas a obovadas, base arredondada a obtusa, ápice arredondado a acuminado, margem plana ou revoluta; face adaxial glabra ou pubescente sobre as nervuras, com um par de glândulas basilaminares ou acropeciolares planas a proeminentes, nervura principal proeminente; face abaxial glabra ou pubescente sobre as nervuras, o restante do limbo raro pubescente, tufos de tricomas presentes ou ausentes na junção das nervuras principal e secundárias; pecíolo inteiro ou canaliculado, glabro ou pubescente, estípulas presentes. Inflorescência axilar ou terminal, bissexuada ou raramente unissexuada (M. minor), panícula ou dicásio, pauciflora ou pluriflora, brácteas caducas na base do pedúnculo, flores pediceladas, subsésseis ou sésseis, díclinas, bractéolas (1-)2-3 ou ausentes. Flores estaminadas monoclamídeas, apétalas, gamossépalas, sépalas concrescidas na base ou até além da metade do cálice; estames 3-10, assentados em disco basal, lobado ou não, glabro ou pubescente, anteras bitecas, basifixas ou dorsifixas, pistilódio presente ou ausente. Flores pistiladas monoclamídeas, apétalas, cálice 5-lobado, ovário glabro ou hirsuto, lóculos uniovulados, estiletes trífidos ou ausentes, estigma bífido, bilabiado 
ou bilobado, inteiro ou rotado, disco basal anelar ou cupulado, glabro ou pubescente, estaminódios presentes ou ausentes. Fruto esquizocarpáceo, tricoca, mericarpos 3, glabros ou pubescente, mesocarpo fibroso. Sementes carunculadas ou sem carúnculas.

Espécie-tipo: Micrandra siphonioides Benth.

Micrandra é um gênero sul-americano, composto por nove espécies, distribuídas desde a Venezuela até o sudeste brasileiro, com centro de diversidade na Amazônia, onde ocorrem oito espécies, podendo ser encontrado em diversos tipos de habitats. Considerando-se o conceito de Prance (1988), as espécies de Micrandra podem ser agrupadas em três padrões de distribuição: 1) Espécie amplamente distribuída: Micradra elata (Didr.) Müll. Arg., com distribuição além do bioma Amazônico, atingindo o Cerrado e Mata Atlântica; 2) Espécies de distribuição restrita: Micrandra siphonioides Benth., M. minor Benth., M. rossiana R.E. Schult., M. lopezii R.E. Schult., M. spruceana (Baill.) R.E. Schult., M. sprucei (Müll. Arg.) R.E. Schult. e M. inundata P.E. Berry \& Wiedenhoeft, com distribuição restrita ao bioma Amazônico. 3) Espécie endêmica: Micrandra gleasoniana (Croizat) R.E. Schult., com registros nas regiões dos rios Mazaruni-Potaro, Guiana, áreas estas conhecidas por apresentarem altas elevações, com terrenos montanhosos e de poucas confluências de rios.

Baldwin \& Schultes (1947) distinguiram Cunuria de Micrandra pelas folhas inteiramente glabras, estípulas glandulares, flores com sépalas concrescidas, ausência de disco basal na flor estaminada, 10 estames e ausência de carúncula nas sementes, propondo quatro espécies e uma variedade (C. spruceana Baill., C. spruceana var. bracteosa (Ducke) R. E. Schult. ex R. E. Schultes \& Baldwin, C. autralis R. E. Schult., C. crassipes Müll. Arg. e C. glabra R. E. Schult.). Posteriormente, Schultes (1952) analisando coleções adicionais, considerou Cunuria um sinônimo de Micrandra, baseado em duas novas espécies (M. rossiana e M. lopezii) que apresentaram disco na flor estaminada e variação de 6-9 estames, desconsiderando a presença ou ausência de carúncula. Jablonski (1967), em um tratamento para as espécies de Micrandra das Guianas, aceitou a decisão de Schultes. No entanto, Webster (1994) e RadcliffeSmith (2001) incluíram Cunuria em suas listas dos gêneros válidos das Euphorbiaceae, não para afirmar sua distinção genérica, e sim para chamar atenção ao problema (Webster 1994, Berry 2004).

De acordo com Webster (1994), Micrandra poderia ser separado de Cunuria por apresentar flores com sépalas livres ( $v s$. flores com sépalas conadas), disco presente nas flores estaminadas ( $v s$. disco ausente), estames 5-8 (vs. estames 8-10) e brácteas florais pequenas ( $v s$. brácteas florais grandes). Entretanto, todas essas características estão presentes ou não em Micrandra, e por essa razão não sustentam o conceito de Cunuria. Neste trabalho, aceitou-se Cunuria como sinônimo de Micrandra, concordando com Schultes (1952), visto que a variação no número de estames é um caráter comum a todas as espécies de Micrandra, assim como a presença ou ausência de carúncula, e não apenas ausente em Cunuria.

Verificou-se que Micrandra tem maiores semelhanças morfológicas com Micrandropsis W. Rodr., do qual se destaca por apresentar anteras elípticas e tricomas simples ( $v s$. anteras lineares, indumento estrelado), além da presença de duas glândula basilaminares na face adaxial da folha (vs. uma única glândula basilaminar); e com Hevea, separando-se deste pelas folhas simples e estames livres (vs. folhas trifolioladas a palmadas e estames conados).

Spruce (1908) relatou o uso das sementes de Micrandra spruceana como alimento (pasta comestível com sabor de queijo) e combustível por índios do alto rio Negro, na Venezuela, extraindo o óleo utilizado para lamparinas. Schultes (1945) informou que os índios do baixo rio Caquetá, na Colômbia, consomem sementes de Micrandra em forma de pasta, após fervura da polpa, pois tais sementes são venenosas, contendo cianeto. De acordo com Schultes (1977), os índios Yakuna e Tanimuka, do rio Miritiparaná, utilizam a pasta ou polpa das sementes de M. spruceana em bolos e no preparo de pão. Para utilização medicinal, Schultes (1978) informou que as tribos indígenas em Boros, vizinhança de Pebas, na Amazônia peruana, usam o látex de M. spruceana para o tratamento de feridas nas gengivas e membranas mucosas da boca, e ainda para estancar o fluxo de sangue após o corte do cordão umbilical. Lorenzi (2002) destacou a madeira de M. elata como de utilidade para produção de forros, confecção de brinquedos, caixotaria, miolos de portas, bem como para fins de paisagismo, devido à copa frondosa. 
Chave para identificação das espécies de Micrandra

1. Folhas com um par de glândulas basilaminares proeminentes ou crateriformes; flores com sépalas concrescidas além da metade do ápice; flores estaminadas com 5-10 estames, não alternissépalos 2. Folhas discolores com um par de glândulas basilaminares crateriformes, face abaxial velutina, nervuras terciárias e squaternárias anastomosadas; inflorescência panícula 2. M. gleasoniana

2. Folhas concolores com um par de glândulas basilaminares proeminentes ou pateliformes, glabras ou esparso-pubescentes na face abaxial, nervuras terciárias e quaternárias não anastomosadas; inflorescência dicásio

3. Folhas com nervação craspedódroma; flores estaminadas com 5-7 estames homodínamos, disco glanduloso; flores pistiladas com ovário assentado em disco cupulado, estilete trífido, livre, estigma bífido, retrorso 9. M. sprucei

3. Folhas com nervação broquidódroma; flores estaminadas com 6-10 estames heterodínamos, disco anelar, tênue; flores pistiladas com ovário assentado em disco anelar, estilete séssil, estigma rotado ou capitado

4. Folhas com tufos de tricomas nas axilas das nervuras principal e secundárias; flores pistiladas com ovário cônico a ovóide, hirsuto, estigma capitado, lobado, aderido ao ápice do ovário 6. M. rossiana

4. Folhas sem tufos de tricomas; flores pistiladas com ovário tereto ou subgloboso, glabro, estigma rotado, bipartido

5. Inflorescência laxa, 3-7 cm compr.; flores agrupadas em raque articulada; pistilódio partido; flores pistiladas com ovário tereto, disco pubescente, estigma foliáceo com terminações arredondadas .... 8. M. spruceana

5. Inflorescência congesta, 1-2 cm compr.; flores densamente aglomeradas pistilódio cônico, inteiro; flor pistilada terminal e duas estaminadas adjacentes; pistilódio cônico, inteiro; flores pistiladas com ovário subgloboso, disco glabro, estigma crasso com terminações afiladas 4. M. lopezii

1. Folhas com um par de glândulas basilaminares planas ou acropeciolares proeminentes; flores com sépalas concrescidas apenas na base; flores estaminadas com 3-6 estames, alternissépalos

6. Folhas com um par de glândulas acropeciolares proeminentes; flores estaminadas com 3-5 estames; flores pistiladas com ovário subgloboso a piriforme, estilete e estigma filiformes 1. M. elata

6. Folhas com um par de glândulas basilaminares planas; flores estaminadas com 5(-6) estames; flores pistiladas com ovário cônico, lobulado, estilete tubular a colunar, estigma bífido ou labiado 7. Folhas sem glândulas diminutas na junção das nervuras principal e secundárias; inflorescência unissexuada; flores estaminadas sem pistilódio; flores pistiladas com estigma labiado, estaminódios raramente presentes, caducos

5. M. minor

7. Folhas com glândulas diminutas na junção das nervuras principal e secundárias, inflorescência bissexuada; flores estaminadas com pistilódio cônico; flores pistiladas com estigma bífido, estaminódios persistentes ou ausentes

8. Folhas sem tufos de tricomas; flores pistiladas com estilete 1-lobulado, estaminódios persistentes .... 3. M. inundata

8. Folhas com tufos de tricomas; flores pistiladas com estilete não lobulado, estaminódios ausentes 7. M. siphonioides

1. Micrandra elata (Didr.) Müll.Arg., Linnaea 34: 142. 1865.

$\equiv$ Pogonophyllum elatum Didr., Vidensk. Meddel. Dansk. Naturhist. Foren. Kjobenhavn 1857: 145. 1857. Tipo. BRASIL. MinAS GERAIS: margem do rio Grande, VII/1834, fl., Lund s.n. (holótipo, G-DC; fotos do tipo, G-DC!).

$\equiv$ Micrandra bracteosa Müll.Arg., Fl. Bras. 11(2): 290. 1873. Tipo. BRASIL. BAHIA: s.l., s.d., fl., Martius s.n. (holótipo, M; fotos do tipo, M!).
三 Micrandra glaziovii Pax, Pflanzenr. 147, 1 (Heft 42): 20. 1910. Tipo. BRASIL. São Paulo: Mogi das Cruzes, (fl.), A. Glaziou 18470 a (lectótipo, P!, aqui designado; isolectótipo, $\mathrm{F}$; fotos do holótipo (original destruído), B! neg. [5410], P!, F!); BRASIL. SÃo PAULO: Araraquara, caminho Romão, 18-IX-1888, (fl.), Loefgren, A. 920 (síntipo, SP!).

$\equiv$ Micrandra brownsbergensis Lanj., Euphorb. Surinam 34, p1. 7, 8. 1931. Tipo. SURINAME. Brownsberg: 31-X-1924, (fl.), Lanjouw 6687 
(lectótipo, RB!, aqui designado; isolectótipos, K, U, W; fotos do tipo, K!, U!); Tipo. SURINAME. Brownsberg: 24-II-1919, (fr.), Lanjouw 4267 (síntipos, K, U, W; fotos do tipo, K!, U!).

$\equiv$ Micrandra santanderensis Croizat, J. Arnold Arbor. 24: 169. 1943. Tipo. COLÔMBIA. SANTANDER: south of Raizudo, 30-IV-1934, (f1.), O.L. Haught 2189 (holótipo, A!; fotos do tipo, A!, NY!).

Figura 1a-g

Árvore 4-30 m alt., 45-120 cm diâm. Ramos glabros. Folhas com nervação broquidódroma, concolores, 9,5-10 × 3,4-4 cm, elíptico-oblongas a elíptico-lanceoladas, cartáceas a subcoriáceas, margem plana, base arredondada a obtusa, ápice acuminado; face adaxial glabra, nervura principal pouco proeminente; face abaxial esparso-pubescente, maior concentração de tricomas sobre as nervuras, tufos de tricomas simples na junção da nervura principal com secundárias, nervuras proeminentes; pecíolo 1,5-2,5 cm compr., canaliculado, glabro, glândulas proeminentes 2 , acropeciolares, ca. $1 \mathrm{~mm}$ diâm. Inflorescência panícula pluriflora, $3-4 \mathrm{~cm}$ compr., bissexuada, terminal, raque 1-2 cm compr., tomentosa, flexível, bráctea ca. $1 \mathrm{~mm}$ compr., caduca. Flores estaminadas com pedicelo 1-1,3 mm compr., pubescente, tricomas simples, bractéola caduca na base do botão, 1,5-2 × $1 \mathrm{~mm}$, elípticoobovada, externamente pubescente, internamente glabra; cálice ca. $3 \mathrm{~mm}$ compr., concrescido na base, 5-lobado, lobos ovais, externamente pubescentes, internamente glandulosos; estames 3-5, homodínamos, alternissépalos, 2-3 mm compr., glabros, um disco lobado, piloso; pistilódio ausente. Flores pistiladas com pedicelos 1-1,5 mm compr., pubescentes, bractéola na base do botão 1-1,3 cm, elíptico-oboval, externamente pubescente, internamente glabra; cálice ca. $3 \mathrm{~mm}$ compr., concrescidos na base, 5-lobado, elípticooblongos, externamente pubescentes, internamente glabros; ovário ca. $2 \mathrm{~mm}$ compr., ca. 2,5 mm diâm., subgloboso a piriforme, hirsuto, disco basal anelar, piloso; estiletes 3 , metade basal hirsuta, estigma filiforme, bífido. Fruto ca. $2 \times 2,5 \mathrm{~cm}$, pedúnculo 3-4 cm compr., mericarpos corrugados, pubescentes a velutinos. Sementes 1,2-1,5 × 0,5-0,7 cm, obovadas, lisas, brilhantes, com manchas irregulares, marrons e beges, rafe plana, conspícua, carunculadas.

Ocorre no Suriname, Guina Francesa, Guiana (Funk et al. 2007), Colômbia, Peru e Brasil (AM, AP, PA, BA, MG e SP). Espécie com distribuição disjunta entre a Amazônia e Mata Atlântica. Bem adaptada a vários tipos de habitats, principalmente em floresta de terra firme, floresta montanhosa, semidecídua, floresta alagada, em solo arenoso, argiloso ou umedecido, mais frequente na transição floresta de terra firme para áreas alagadiças. $\mathrm{O}$ material coletado por $A$. Roa 360, no rio Mesay, representa um novo registro de ocorrência para Caquetá, na Colômbia. Floresce praticamente o ano inteiro e frutifica entre setembro e dezembro. Os frutos amadurecem em consonância com o período de floração, com poucas flores remanescentes entre os meses de janeiro a junho. Nomes vulgares: Peru. rio Amazonas: "seringarana". Suriname: "bartabalie balli" e "koedi biosé balli" (Arawak), "moereidam" e "topoeloe alomé" (Karib). Brasil. rio Solimões: "seringarana". rio Paraná: "árvore de mamona" (Schultes 1979). São Paulo: "leiteiro-branco" (Lorenzi 2008), "mamoninha", "mamona de árvore". Minas Gerais: "leiteiro ou mamona do mato". Bahia: “mamoninha”, J.C. Jardim 1264, SP).

Material selecionado. BRASIL. AmAPÁ: Território Federal do Amapá, entre acampamento Carnot e Cunani, 10-XI-1979, (fl.), D.F. Austin et al. 7365 (MG, INPA, MO, NY). AmazonAs: Estrada de ManausItacoatiara, km 155, 11-VII-1968, (fl.), W. Rodrigues et al. 8508 (MG, IAN, INPA, NY). BAHIA: Almadina, estrada ca. $5 \mathrm{~km} \mathrm{~W}$ da sede, Fazenda Cruzeiro do Sul, 21-25-I-1998, (fr.), J.G. Jardim et al. 1264 (NY, SP). Minas Gerais: Perdizes, Mata do Alaor, 26-IX-1994 (fl.), E. Tameirão Neto et al. 1582 (MG, SP). PARÁ: Rodovia Belém-Brasília, km 96, 28-IX-1959 (fl.), M. Kuhlmann \& S. Jimbo 312 (MG, IAN, INPA, NY, SP, UEC,). São Paulo: Município de Gália, Estação Ecológica dos Caetetus, Trilha do Paraíso, entre o $1^{\circ}$ e $2^{\circ}$ lagos, 12-VII-2000, (fl.), P. Fiaschi e A.V. Christianini 374 (SP, SPF). COLÔMBIA. CAQuetá: rio Mesay, 15-III-1976, (fr.), A. Roa 360 (INPA). GUIANA FRANCESA. Montagne de Kaw, 12-XII-1954, (fl.), R.S. Cowan 38748-A (INPA, RB). SURINAME. SipaLIwINI: Vicinity of Blanche Marie Waterfall on the Nickerie River, $04^{\circ} 45^{\prime} 30^{\prime \prime} \mathrm{N}$ 56 52'50"W, s.d., (fl.), R. Evans et al. 2458 (IAN, MO, P, RB). PERU. LORETO: Reserva Nacional Allpahuayo-

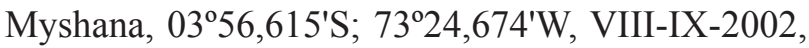
est., I. Mesones 57 (F). VENEZUELA. ZuLIA: $9^{\circ} 36^{\prime} \mathrm{N}$; $72^{\circ} 52^{\prime} \mathrm{W}, 26-\mathrm{III}-1982$, fl., fr., R. Liesner \& A. Gonzalez s.n. (MG, VEN).

Pax (1910) descreveu Micrandra glaziovii, a partir da coleta feita por Glaziou 18470a, em Mogi das 

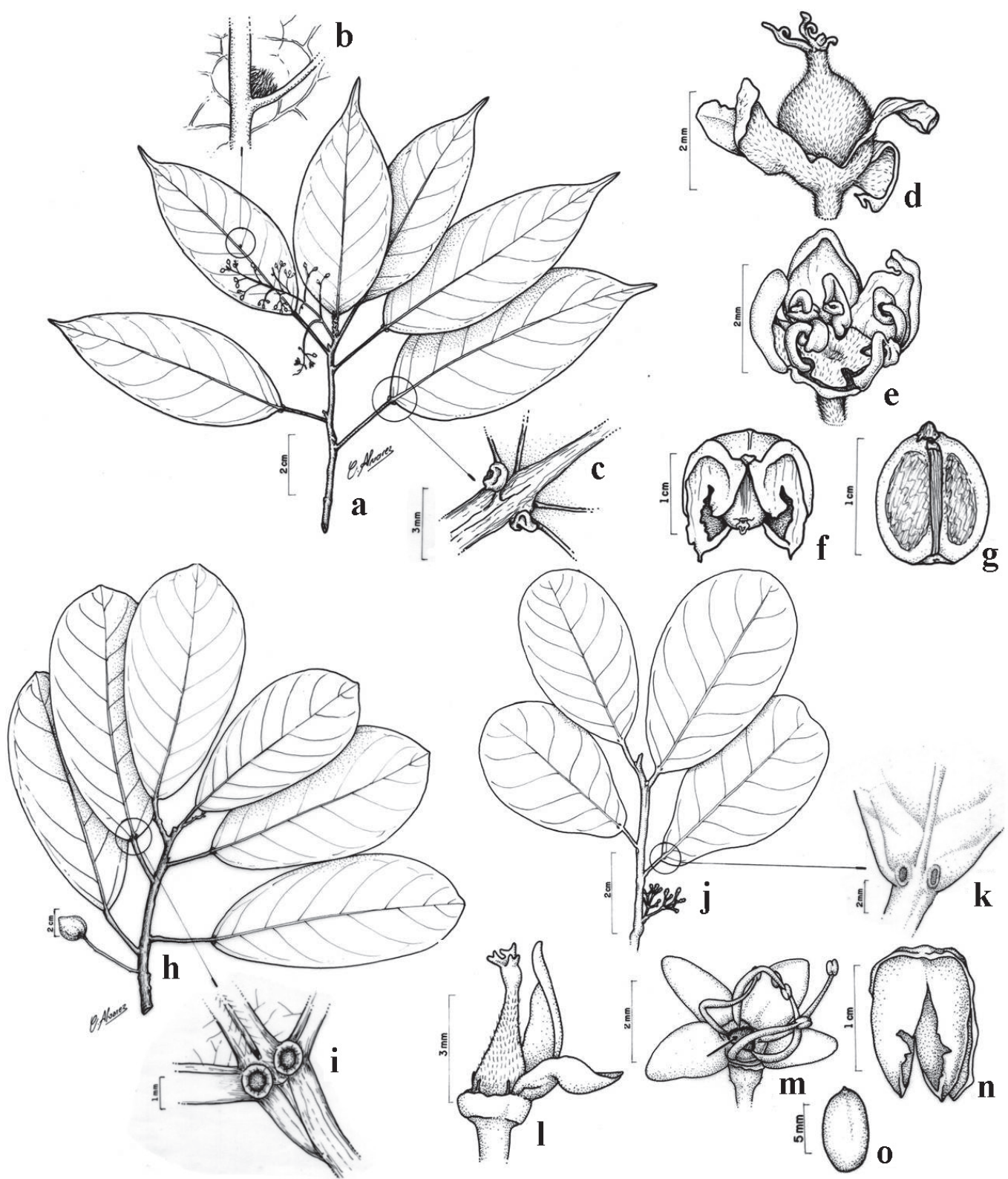
Cruzes e por Loefgren 920, em Araraquara, São Paulo. Schultes (1979) a sinonimizou com M. elata. No entanto, as duplicatas de Glaziou 18470 a estão citadas nos herbários como isótipos, não havendo registro de holótipo, que foi destruído na Segunda Guerra Mundial. Sendo assim, aqui é designado o lectótipo (Glaziou 18470a, P), por apresentar o material bem preservado com as inflorescências representadas por flores pistiladas e estaminadas.

Lanjow (1931) descreveu M. brownsbergensis, mas não observou os materiais de M. elata, separando-a por comparações feitas com materiais de $M$. siphionioides e $M$. heterophylla, esta última aqui considerada nomina nudum. O autor citou vários espécimes como síntipos (Lanjouw 6687, 1924, Lanjouw 4267, 1919, Lanjouw 4701, 1920, Lanjouw 3233, 1917, Lanjouw 6721, 1924, Lanjouw 6537, 1924). A designação do lectótipo RB (Lanjouw 6687) baseia-se na presença das inflorescências e flores pistiladas, que nitidamente representam um caráter forte para a identificação da espécie.

Schultes (1979) examinou os tipos de M. glaziovii, M. brownsbergensis, $M$. santanderensis e $M$. bracteosa e sinonimizou todas em M. elata, relatando que a ausência ou fraca presença de glândulas, panícula curta, presença de tufos de tricomas nas axilas das nervuras na face adaxial das folhas e tamanho do fruto, por si só, não separam os taxa.

Micrandra elata tem semelhanças morfológicas com M. siphonioides, por apresentarem folhas com tufos de tricomas simples na junção da nervura principal com as secundárias, flores estaminadas com estames alternissépalos, flores pistiladas com ovário hirsuto, disco anelado e estiletes 3, bífidos, glabros. Porém, M. elata diferencia-se facilmente por apresentar folhas elípticooblongas a elíptico-lanceoladas, um par de glândulas acropeciolares na extremidade da lâmina foliar, flores estaminadas com variações de 3-5 estames, ausência de pistilódio, flores pistiladas com ovário piriforme a subgloboso, não lobulado, e estilete e estigma filiformes. Em exsicatas da região Sudeste do Brasil, é possível observar o deslocamento das glândulas acropeciolares em direção à borda da lâmina foliar.

2. Micrandra gleasoniana (Croizat) R.E. Schultes, Bot. Mus. Leafl. 15(8): 203. 1952.

$\equiv$ Cunuria gleasoniana Croizat, Bull. Torrey Bot. Club 67: 289. 1940. Tipo. GUIANA. Arubaru River, upper Mazaruni drainage, near Haiamatipu Mountain, 4-II-1939, (fr.), A.S. Pinkus 176 (holótipo, A!; fotos do tipo, A!, S!, F!, US!, NY!)

Figura $1 \mathrm{~h}-\mathrm{i}$
Árvore 10-18 m alt., 35-41 cm diâm. Ramos estriados, pubescentes, tricomas simples, híspidos. Folhas com nervação broquidódroma, discolores, 11-17 × 7-8 cm, elíptico-obovadas a obovadas, coriáceas, margem revoluta, base obtusa, ápice levemente acuminado; face adaxial glabra, nervura principal proeminente, secundárias, terciárias e quaternárias conspícuas, planas, com par de glândulas basilaminares proeminentes, crateriformes, $1-1,3 \mathrm{~mm}$ diâm.; face abaxial velutina, ferrugíneos, em maior concentração sobre as nervuras, a principal proeminente, secundárias, terciárias e quaternárias proemimentes, anastomosadas; pecíolo 1,5-3 cm compr., canaliculado, crasso, ruguloso, pubescente. Inflorescência panícula pauciflora, subterminal, axilar, adpressa, raque tomentosa, pedúnculo crasso, ca. $3 \mathrm{~cm}$ compr. Flores estaminadas e pistiladas não vistas. Fruto com mesocarpo levemente corrugado, seríceo, cocas ca. 1,8 $\times 1 \mathrm{~cm}$, mericarpo fibroso, estilete persistente. Sementes lisas, rafe pouco proeminente, ca. 1,2 $\times 0,8 \mathrm{~cm}$, carunculadas.

Ocorre na Guiana. Devido ao pouco material analisado seria tendencioso classificar essa espécie como rara. Todavia, a consideramos um provável endemismo para a região de Mazaruni, na Guiana. A carência de material em floração não permite delimitar com exatidão a fenologia, entretanto, nos materiais analisados verificou-se que a espécie frutifica em fevereiro e junho.

Material selecionado. GUIANA. Upper Mazaruni Region, Pakaraima, 5²4'N, 60 $18^{\prime} \mathrm{W}, 15-\mathrm{VI}-1986$, (fr.), J.J. Pipoly \& Ken Alfred 7843 (INPA).

A representação de $M$. gleasoniana resume-se a duplicatas dos materiais-tipo e nas coleções de Pinkus 274 e 176, Maguire \& Fanshawe 32296 e Pipoly \& Alfred 7843, da Guiana, depositadas no herbário $\mathrm{MO}$, a última também representada no INPA. Estes exemplares encontram-se apenas com frutos, o que dificultou sua completa descrição e sugerir suas relações morfológicas; mas, a consistência foliar com margem revoluta, a forma das glândulas basilaminares crateriformes e a presença de indumento na face abaxial da folha facilitaram a identificação da espécie. Micrandra gleasoniana aproxima-se de $M$. siphonioides pelas folhas elíptico-obovadas, com base obtusa, ápice discretamente acuminado e fruto com estilete persistente. Entretanto, M. gleasoniana diferencia-se facilmente por apresentar folhas discolores, pilosidade ferrugínea nas nervuras e no restante do limbo na face abaxial, margem revoluta e glândulas basilaminares crateriformes na face adaxial. 
3. Micrandra inundata P.E. Berry \& Wiedenhoeft, Syst. Bot.29(1): 127-133.2004. Tipo. VENEZUELA. Seasonally flooded banks of black-water rio Temi, 1-2, km above Yavita. 16-XI-1996, (fl.), P.E. Berry \&

J. Rosales 6350 (holótipo, MO; isótipo, MG!; fotos do tipo, MO!, US!, F!, DAV!, MICH!).

Figura $1 \mathrm{j}-\mathrm{o}$

Árvore 5-12 m alt., 10-50 cm diâm., tronco com duas ou mais ramificações emergindo da base, cada uma com 10-50 cm diâm., raízes adventícias 1-2 m. Ramos esparso-pubescentes, eretos. Folhas com nervação broquidódroma, concolores, 3-10 × 1,5-5 cm, elípticoobovadas a obovadas, coriáceas, pubescentes, margem inteira, plana, base cuneada, ápice arredondado a levemente agudo; face adaxial glabra, nervura principal proeminente, par de glândulas basilaminares, planas, 0,5-1 mm diâm., glândulas diminutas na junção das nervuras principal e secundárias; face abaxial esparso-pubescente sobre a nervura principal, restante do limbo raramente pubescente; pecíolo 0,7-1,5 cm compr., pubescente, incanos, estípulas laterais, lanceoladas, puberulentas. Inflorescência panícula bissexuada, axilar, pauciflora, laxa, 2-6 cm compr., pubescente, pedúnculo 5-8 mm compr. Flores estaminadas com pedicelo 1-2,5 mm compr., pubescente. Cálice 3-4 × 1-2 mm, 5-lobado, lobos concrescidos na base, elíptico-oblongos, externamente pubescentes, internamente esparso-pubescentes a glandulosos; estames 5, homodínamos 2-4 mm compr., alternissépalos, pilosos, disco basal pentalobado, anteras bilobadas, pistilódio no centro do disco, ca. $1 \mathrm{~mm}$ compr., cônico, densamente piloso. Flores pistiladas com pedicelo 2-3 mm compr., pubescente. Cálice 5-6 × ca. $2 \mathrm{~mm}, 5$-lobado, lobos concrescidos na base, elíptico-oblongos, levemente retrorsos, caducos, externamente pubescentes, internamente glandulosos; ovário ca. $2 \mathrm{~mm}$ compr., piramidal, hirsuto, lobulado, assentado sobre disco basal anelar, circundado por estaminódios persistentes, ca. $1 \mathrm{~mm}$ compr., alternissépalos, estilete trífido, tubular, ca. $1 \mathrm{~mm}$ compr., 1-lobulado, ramos bífidos. Fruto 1,5-2 × 1-1,3 cm, mericarpos esparso-pubescentes, mesocarpo fibroso, estilete persistente. Sementes ca. $1 \times 0,6 \mathrm{~cm}$, apiculadas, lisas, de cor bronze, sem carúnculas.

Ocorre na Venezuela, com nítida adaptação às florestas sazonalmente inundadas de água preta dos afluentes do rio Orinoco, tais como Temi, Ribeiras do Canal Ucata e Atabato, e afluentes do rio Negro, como o canal São Miguel e Baría. A pouca representatividade de materiais coletados de $M$. inundata dificulta definir com precisão sua fenologia, indicando apenas que floresce entre novembro e março, e frutifica entre março e junho. Nomes vulgares: "Palo de boya" e "palo de boya chivudo" (Venezuela, Berry \& Wiedenhoeft 2004).

Material selecionado. VENEZUELA. AMAZONAs: rio Temi, 0255'04"N; 67²4'29"W, 18-XI-1996, (fl.), P.E. Berry \& J. Rosales 6393 (GH, MG, K, MO, NY, VEN).

Micrandra inundata é reconhecida pelo hábito com raízes adventícias, folhas elíptico-obovadas a obovadas, com ápice arredondado, bem como hábitat em áreas inundadas, que deu origem ao epíteto específico (Berry \& Wiedenhoft 2004). Tem semelhança morfológica com M. minor, conforme já assinalado por Berry \& Wiedenhoeft (2004), porém, essa apresenta estaminódios caducos, e os lobos do cálice nas flores pistiladas às vezes ausentes, ao contrário de $M$. inundata, cujos estaminódios são persistentes. Além disso, M. inundata exibe pecíolo e pedicelos mais curtos, frutos menores, madeira menos densa e, principalmente, habitat em florestas sazonalmente alagadas.

Micrandra inundata apresenta semelhança morfológica com $M$. siphonioides, por ambas apresentarem folhas elíptico-obovadas a obovadas, glândulas basilaminares planas, flores estaminadas com cinco estames, alternissépalos, disco basal pentalobado, flores pistiladas com ovário hirsuto, lobulado e estilete trífido, enquanto que $M$. inundata apresenta folhas com ápice arredondado, inflorescências menores com pedicelos curtos, flores pistiladas com estaminódios persistentes e estilete 1-lobulado.

4. Micrandra lopezii R.E. Schultes, Bot. Mus. Leafl. 15(8): 204-211. 1952. Tipo. BRASIL. Amazonas: rioUaupés, at base of Serra Tukano, 08/II/1948, Schultes \& López 9725 (holótipo, GH; isótipos, GH, IAN!, P; fotos do tipo GH!, P!) $\equiv$ Micrandra lopezii forma anteridifera R.E. Schultes, Bot. Mus. Leafl. 15(8): 210-211. 1952. Tipo. BRASIL. Upper rio Negro basin: rio Curicuriari, base of Serra Cupibi, 22/I/1948, (fl.), R.E. Schultes \& F. López 9637 (holótipo, GH; fotos do tipo, GH!), syn. nov.

Figura 2a-g

Árvore 15-21 m alt., 20-60 cm diâm. Ramos glabros, levemente estriados, par de estípulas apicais, lanceoladas, pubescentes. Folhas com nervação broquidódroma, concolores, 8-15 × 4,5-7,5 cm, 
elíptico-arredondadas a elíptico-oblongas, coriáceas, margem levemente revoluta, base cordada, ápice arredondado a levemente acuminado; face adaxial glabra, nervura principal proeminente, par de glândulas basilaminares, pateliformes, 0,7-1 mm diâm.; face abaxial glabra, nervuras proeminentes; pecíolo 2-4 cm compr., canaliculado, crasso, glabro. Inflorescência dicásio, congesto, terminal, bissexuado, articulado, curto, 1-2 cm compr., raque $2-4 \mathrm{~mm}$, tomentosa, flores densamente aglomeradas, flor pistilada terminal, duas flores estaminadas adjacentes, 2-3 bractéolas involucrais, ovais, cuculadas, caducas, 1,2-2 mm compr., esparsamente pubescentes, botões florais fortemente imbricados. Flores estaminadas sésseis, pubescentes; cálice ca. 2,5 mm compr., 5-lobado, lobos concrescidos além da metade, oblongos, pubescentes externamente, internamente tomentosos; estames 6-9, heterodínamos, curtos, 0,5-1 mm compr., glabros, assentados em disco basal, tênue, externamente glabro, internamente hirsuto, anteras dorsifixas, pistilódio hirsuto, cônico. Flores pistiladas sésseis, pubescentes; cálice $2-3 \mathrm{~mm}$, 5-lobado, lobos concrescidos além da metade, elípticooblongos, externamente pubescentes, internamente tomentosos; ovário ca. $1 \mathrm{~mm}$ compr., subgloboso, glabro, corrugado, disco basal anelar, glabro, estilete séssil, estigma rotado, bífido, crasso, glabro, com terminações afiladas, estaminódios ca. 0,5 mm compr., crassos, ápice levemente avermelhado. Fruto 2,5-3 $\times 2-2,5 \mathrm{~cm}$, mericarpos corrugados, retorcidos, glabros, mesocarpo fibroso. Sementes ca. 1,5 cm compr., elíptico-obovadas, lisas, brilhantes, pretas, rafe proeminente, conspícuas, sem carúncula.

Ocorre no apenas Estado do Amazonas (Brasil), na margem do rio Uaupés, às proximidades da serra do Tucano, a poucos quilômetros da cidade de Bela Vista, pois boa parte do material encontra-se sem locais e datas de coleta. Esta região é reconhecida como centro de diversidade de muitas espécies vegetais (Baldwin \& Schultes 1947). A ausência das datas de coleta impossibilitou o registro de floração e frutificação.

Material selecionado. BRASIL. Amazonas. rio Uaupés, s.d., (fl.), R.E. Schultes 9663 (parátipo, IAN!); s.1., s.d., (fl.), R.E. Schultes 9664 (parátipo, IAN!); s.1., s.d., (fl., fr.), R.E. Schultes 9666 (parátipo, IAN!); s.1., s.d., (fl., fr.), R.E. Schultes 9667 (parátipo, IAN); s.l., s.d., (fr.), R.E. Schultes 9669 (parátipo, IAN!).

Schultes (1952), ao estabelecer Micrandra lopezii, propôs relações morfológicas com M. glabra, diferenciando a primeira por apresentar folhas maiores, frutos menores com ápice arredondado, flores estaminadas menores e inflorescência extremamente contraída e aglomerada. No mesmo trabalho, aquele autor estabeleceu $M$. lopezii fo. anteridifera, baseando-se no material coletado à beira do rio Ciricuriari, na serra do Cujubí, AM, caracterizando-a por maior tamanho e espessura do tronco, assim como folhas menos coriácea. Entretanto, verificou-se que as características destacadas para M. lopezii fo. anteridifera não são consistentes, razão pela qual a forma é considerado sinônimo.

Micrandra lopezii mantém relações morfológicas com M. spruceana pelas semelhanças florais e pelo fato de apresentarem um par de estípulas apicais ou terminais, característica marcante de $M$. spruceana. No entanto, $M$. lopezii exibe inflorescências curtas, terminais, densamente aglomeradas e a organização das flores pistiladas e estaminadas no ápice de cada raque, com 2-3 bractéolas côncavas, caducas, envolvendo as flores, em M. spruceana as bractéolas são persistentes. Examinando-se os materiais-tipo, constatou-se a ocorrência de uma anomalia, destacada por Schultes (1952): flores pistiladas com estames providos de anteras, o que provocaria uma exclusividade dentro da família, ou seja, flores bissexuadas. Porém, a análise de outras flores pistiladas mostrou que na presença de estames férteis o estigma não é funcional ou o ovário não possui óvulos. Portanto, neste trabalho considerou-se esta estrutura como pistilódio.

5. Micrandra minor Benth., Hooker's J. Bot. Kew Gard. Misc. 6:371. 1854. Tipo. BRASIL. AmazonAs: rio Uaupés, X/1852, (fl.), Spruce R. 2479 (isótipo, $\mathrm{MG}$ !, P; fotos do tipo, P!).

$\equiv$ Micrandra siphonioides var. minor (Benth.) Müll. Arg., Prodr. 15(2): 710. 1866.

Figura $2 \mathrm{~h}-\mathrm{m}$

Árvore ou arbusto 4-40 m alt., 30-150 cm diâm. Ramos glabros. Folhas com nervação broquidódroma, concolores, 8,5-10 × 3,5-4,5 cm, elípticas a obovadas, cartáceas, margem inteira com tricomas simples, esparsos, base obtusa, ápice acuminado; face adaxial glabra, nervuras planas, com um par de glândulas basilaminares, planas, ca. 1 mm diâm.; face abaxial com nervuras pubescentes, esparsos, estrigosos, restante do limbo glabro, nervura principal proeminente; pecíolo 1,5-3 cm compr., canaliculado, esparso-pubescente. Inflorescência panícula unissexuada, 7-9,5 cm compr., axilar ou terminal, laxa, raque 2-3 cm compr., pubescente, bráctea ca. $1,5 \times 1 \mathrm{~mm}$, triangular, caduca, 

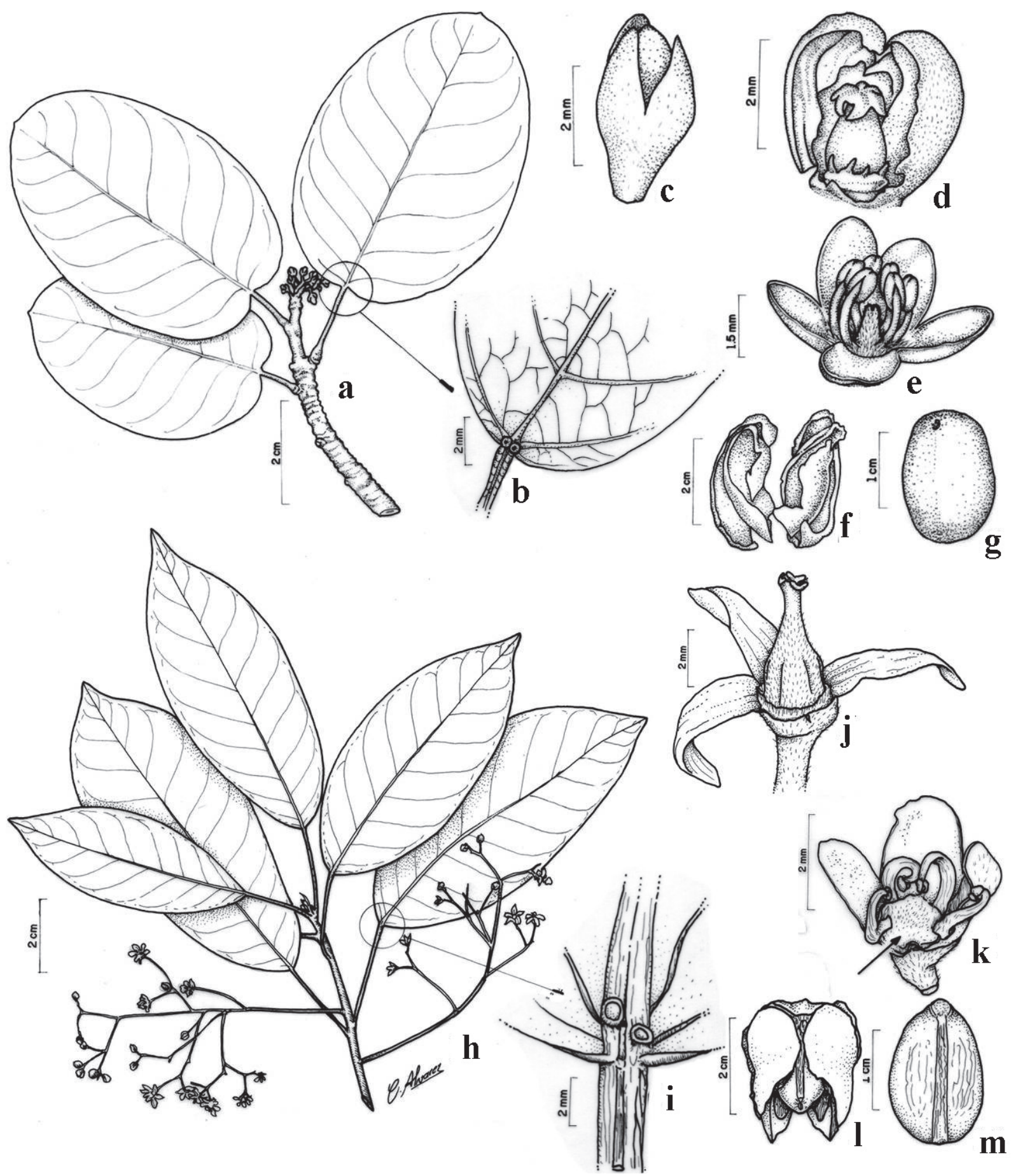

Figura 2. a-g. Micrandra lopezii R. E. Schult. a. Ramo com inflorescência. b. Glândulas basilaminares na face adaxial do limbo. c. Botão floral envolvido por 3 bractéolas. d. Flor pistilada mostrando o disco basal anelar e estaminódios. e. Flor estaminada com dois estames removidos, destacando o pistilódio discretamente bífido. f. Mericarpo retorcido. g. Semente sem carúncula (a-e: R.E. Schultes 9725; f-g: R.E. Schultes 9660). h-m. Micrandra minor Benth. h. Ramo com inflorescência. i. Glândulas basilaminares na face adaxial do limbo. j. Flor pistilada. k. Flor estaminada com disco lobado. 1. Mericarpo com semente. m. Semente sem carúncula (h-i: R.E. Schultes 24510; j-k: P.J.S. Sousa 1; 1-m: L. Coêlho et al. 387).

Figure 2. a-g. Micrandra lopezii R. E. Schult. a. Branch with inflorescence. b. Basilaminar glands on adaxial leaf surface. c. Floral bud, surrounded by 3 bracteoles. d. Pistillate flower with basal annular disc and staminodes. e. Staminate flower with two stamens removed, howing the bifid pistillode. f. Twisted mericarp. g. Ecarunculate seed (a-e: R.E. Schultes 9725; f-g: R.E. Schultes 9660). h-m. Micrandra minor Benth. h. Branch with inflorescence. i. Basilaminar glands on adaxial leaf surface. j. Pistillate flower. k. Staminate flower with lobed disk. 1. Mericarp with seed. m. Ecarunculate seed (h-i: R.E. Schultes 24510; j-k: P.J.S. Sousa 1; 1-m: L. Coêlho et al. 387). 
externamente pilosa, internamente glabro. Flores estaminadas com pedicelo 3-4 mm compr., pubescente; cálice ca. $1 \mathrm{~mm}$ compr., 5-lobado, lobos concrescidos na base, ovais, externamente pilosos, internamente glanduloso; estames 5, homodínamos 3-4 mm compr., alternissépalos, filetes pubescentes, disco basal pentalobado, lobos triangulares a retangulares, densamente pubescentes no centro do disco, pistilódio ausente. Flores pistiladas com pedicelo 3-4 mm compr., pubescente; cálice 4-5 × ca. $2 \mathrm{~mm}, 5$-lobado, lobos concrescidos na base, $4 \mathrm{~mm}$ compr., elípticooblongos, pubescentes externa e internamente; ovário, ca. $2 \mathrm{~mm}$ compr., ca. $2 \mathrm{~mm}$ diâm., cônico, lobulado, hirsuto, assentado em disco basal anelar, piloso, estilete colunar, inteiro, ca. $1 \mathrm{~mm}$ compr., glabro, estigma 3, labiado, estaminódios presentes ou não, caducos. Fruto ca. $3 \times 2,5 \mathrm{~cm}$, mericarpos corrugados, esparso-pubescentes, mesocarpo fibroso, pedúnculo $5 \mathrm{~cm}$ compr. Sementes 1,5-2 × 1-1,5 cm, obovóides, marrom-escuras, levemente corrugadas, rafe proeminente, cicatrizes inconspícuas, sem carúncula.

Ocorre no Brasil (AM e PA), Venezuela (Bolívar), Peru (Putumayo) e Colômbia (Puerto Asis), sendo esta última uma nova ocorrência. Habita ambientes de terra firme de solo arenoso e argiloso, e áreas alagadas próximo a igarapés e rios. Floresce de maio a setembro, e frutifica de setembro a março. Nomes vulgares: Colômbia. rio Papurí: "bu-háwak-puh" (Tukano); rio Igaparaná: "efacone" e "huermega" (Witoto), "wakati-erwicheri" (Bora); rio Vaupés: "ma-há-puch" e "ma-há-puh” (Tukano), "man-jé-ka" (Kubeo), "wer-merger" (Witoto); rio Kananarí: "ma-há-ree" (Taiwano); rio Piraparaná: "ma-há-wa-he" ("semente de arara") (Makuna) e "ma-há-wa-hö" ("semente de arara") (Barasana); rio Apaporis: "pý-root" (Puinave), "woo-sheen"” (Puinave). Peru. rio Amazonas: "seringarana"; rios Putumayo e Caquetá: "huemega" ou "wakati Ewickeri” Venezuela. Marquiritare: "caucho Kunudi”. Territótio Federal: "caucho de guaco" e "caucho de invierno"; rio Caurá: "caucho". Brasil. rio Uaupés: "arara-seringa"; rio Solimões: "cauchorana"; rio Negro: "seringá irari”; rio Solimões: "seringarana" (Schultes, 1979); rio Aracá: "aracá-seringa".

Material selecionado. BRASIL. AmazonAs: Alto rio Negro, 00²1'09"S, 6354'40"W, 16-VII-1996, (fl.), P. Acevedo-Rdz. et al. 8397 (INPA). PARÁ: Belém, seringal do Baldwin, Embrapa, ao lado do setor de produção de mudas, P.J.S. Souza 01 (IAN, MG).
COLÔMBIA. rio Putumayo, s.d., (fl.), W. Fox 60 (MG). VENEZUELA. BolívAR: rio Kakaro, afluente del Erebato, VIII-1942, (fl.), F. Cardona 431 (IAN).

Micrandra minor muitas vezes foi confundida com M. siphonioides nas identificações em herbários. Bentham (1854), ao estabelecer Micrandra minor, a caracterizou pelas folhas, com pecíolos curtos e inflorescências dióicas menores, e pedicelos curtos. Posteriormente, Müller (1866) a considerou como variedade de Micrandra siphonioides, estabelecendo M. siphonioides var. minor, baseado no menor tamanho das folhas, laceolado-obovadas, acuminadas, inflorescência com poucas flores e frutos menores. O mesmo autor, em 1873, desconsiderou as características citadas para a variedade e sinonimizou M. siphonioides var. minor e M. minor em M. siphonioides. Pax (1910) manteve $M$. siphonioides var. minor e $M$. minor como sinônimo de M. siphonioides, tratando-a como polimorfa. No entanto, Schultes (1968) restabeleceu M. minor como válida, caracterizando-a por não apresentar sapopemas e folhas sem tufos de tricomas, glabras, enquanto em M. siphonioides há grandes raízes sapopemas e presença de tufos de tricomas. Recentemente, Funk et al. (2007), ao publicar o checklist das plantas do escudo das Guianas, incluíram M. siphonioides var. minor como sinônimo de M. minor, também considerada no presente trabalho.

Tanto Micrandra minor quanto $M$. siphonioides compartilham folhas elípticas a obovadas, flores estaminadas com cinco estames alternissépalos, cálice concrescido na base das sépalas, disco basal 5-lobado, com o centro denso-piloso de tricomas simples e flores pistiladas com ovário lobulado, hirsuto, com estilete trífido, glabro. Porém, M. minor diferencia-se por apresentar folhas sem tufos de tricomas na junção das nervuras principal com as secundárias na face abaxial, flores estaminadas sem pistilódio no centro do disco, flores pistiladas com estilete inteiro, colunar, quase filiforme e sementes sem carúnculas.

6. Micrandra rossiana R.E. Schult., Bot. Mus. Leafl. 15:201.1952. Tipo. BRASIL.AmAZONAs: rioUaupés, igarapé da Chuva, Taracuá, 12-XI-1947, (fl.), R.E. Schultes \& J.M. Pires 9058 (holótipo, GH; isótipos, $\mathrm{P}$, U, US; fotos do tipo, GH!, K!, P!, U!, US!) Figura 3a-g

Árvore 7-35 m alt., 10-77,6 cm diâm. Ramos esparsamente pubescentes. Folhas com nervação broquidódroma, concolores, 5,7-15,5 × 2,2-8 cm, elíptico-oblongas a obovadas, cartáceas a subcoriáceas, 
margem inteira, plana, glabra, base obtusa, ápice acuminado a apiculado; face adaxial glabra ou esparsopubescente, com nervura principal pouco proeminente, um par de glândulas basilaminares proeminentes, 1-1,5 mm diâm., circundadas por tricomas simples; face abaxial com tufos de tricomas simples na junção das nervuras principal com as secundárias, nervuras proeminentes, esparso-pubescentes; pecíolo 1-2,6 cm compr., inteiro, raramente canaliculado, pubescente, estípulas ausentes. Inflorescência panícula 2,1-2,5 cm compr., bissexuadas, axilares, paucifloras, com uma flor terminal e duas adjacentes, pedúnculo $0,5-1 \mathrm{~cm}$ compr., grácil, pubescente, brácteas 1,5-2 mm compr., caducas, externamente e internamente pubescentes, bractéola caducas nos botões das flores adjacentes, 0,8-1 cm compr., pilosas. Flores estaminadas com pedicelos das flores terminais $0,4-1 \mathrm{~cm}$ compr., pubescentes, pedicelos das flores adjacentes, 1-2 mm compr., pubescentes; cálice, 2-3 mm compr., 5-lobado, lobos concrescidos além da metade, oblongos a obtusos, externamente pubescentes, internamente glandulosos a papilosos; estames 8 , heterodínamos, 5 externos, ca. 2,2 mm compr., 3 internos, ca. 1,2 mm compr., eretos, glabros, pistilódio $1,5 \mathrm{~mm}$ compr., fusiforme, densamente piloso, ápice glabro, disco basal tênue, concrescido na base dos estames. Flores pistiladas com pedicelo $0,5-1 \mathrm{~cm}$ compr., pubescente; cálice 3,5-4 mm compr., 5-lobado, lobos concrescidos além da metade, oblongos a obtusos, externamente pubescente, internamente pubescentes a papilosos; ovário 1,5-1,8 mm compr., cônico a ovóide, hirsuto, disco basal anelado, glabro, estilete séssil, estigmas 3 , capitado, lobados, glabros, arredondados, aderidos ao ápice do ovário, estaminódios pouco desenvolvidos. Fruto 3,7-4 × ca. $3 \mathrm{~cm}$, mericarpos 3, raramente corrugados, esparso-pubescentes, mesocarpo liso a fibroso, pedúnculo 3-4 cm compr. Sementes 2,3-2,5 × 1-1,2 cm, oblongas, lisas, beges a marrons, rafe plana, conspícua, escurecida, carunculadas.

Ocorre na Colômbia, Venezuela, Equador, Peru (Tropicos 2010) e Brasil (AM, PA e RR). Floresce entre maio e dezembro, e frutifica entre setembro e abril. Nomes Vulgares: Colômbia. rio Uaupés: "bo-wápuch" (Tukano); rio Papurí: "bu-há-wak-puh" (Tukano); rio Piraparaná: "ma-há-wa-pö-kö" (Barasana), "na-hoó-gaw-hê" (Raudal) (Schultes, 1979). Brasil. Amazonas. Tefé: "abiurana cuqui".

Material selecionado. BRASIL. AmAZONAS: Estrada Manaus-Itacoatiara, km 130, 22-VIII-1968, (fl.), W. Rodrigues et al. 8522 (INPA, UEC); AMAZONAs:
Tocantins, mata de terra firme ao longo de um riachinho, 10-II-1944, (fr.), A. Ducke 1560 (parátipo, MG, R); igarapé da Chuva, Taracuá, rio Vaupés, between Ipanoré and confluence with rio Negro, 12-XI-1947, (fl.), R.E. Schultes \& J.M. Pires 9064 (parátipo, IAN). PARÁ: Missão Cururú, 9-V-1977, (fl.), N.A. Rosa \& M.R. Santos 1857 (MG). RoRAIMA: serra Tepequem, beside igarapé Paiua, 19-II-1967, (fr.), G.T. Prance et al. 4556 (INPA, MG, MO, NY, R). COLÔMBIA. rio Piraparaná, 30-VIII-1952, (fl.), R.E. Schultes \& I. Cabrera 17103 (RB). EQUADOR. Pastaza, pozo petrolero "Masarumu" de UNOCAL, 0044'S; 7652'W, 1-17-V-1990, (fr.), S. Espinoza 158 (CR, DAV, MO, QCNE). VENEZUELA. Bolívar: Distrito Piar, $5^{\circ} 55^{\prime} \mathrm{N}, 63^{\circ} 13^{\prime} \mathrm{W}, 8-\mathrm{V}-1986$, (fl.), B. Holst \& R. Liesner 2818 (VEN).

Schultes (1952), ao analisar a coleção Ducke 1560, identificou como Micrandra siphonioides; entretanto, ao analisar coleções adicionais procedentes do alto rio Negro, encontrou características intermediárias, tais como: tufos de tricomas na junção das nervuras principal com as secundárias na face abaxial das folhas, flores campanuladas pentalobadas, disco lobulado na flor estaminada com oito estames, disco anelar na flor pistilada e mericarpo fino, as quais foram básicas para propor Cunuria como um sinônimo de Micrandra. Sendo assim, propôs M. rossiana em homenagem ao casal de missionários, Sr. e Sra. William Arlie Ross, que hospedava os cientistas para a realização das pesquisas no alto rio Negro.

O exemplar R. E. Schultes \& I. Cabrera 14282, depositado no herbário do Missouri Botanical Garden (MO), foi identificado erroneamente como M. kubeorum, nome nudum, porém é M. rossiana. Nowicke (1994), no trabalho de análise palinológica da subfamília Crotonoideae, utilizou esse material.

Micrandra rossiana exibe semelhança morfológica com $M$. elata e $M$. siphonioides pela forma das folhas, tufos de tricomas simples nas axilas das nervuras principal com as secundárias, flores pistiladas com ovário hirsuto e disco anelado. Contudo, M. rossiana separa-se de M. elata e M. siphonioides pelas inflorescências paucifloras, flores com cálice concrescido além da metade, flores estaminadas com oito estames, flores pistiladas com estilete séssil e estigmas capitados, lobados.

7. Micrandra siphonioides Benth., Hooker's J. Bot. Kew Gard. Misc. 6: 371. 1854.

三 Micrandra major Baill., Adansonia 4: 286. 1864. Tipo. BRASIL. PARÁ: s.1., s.d., fl., Jerreira s.n. (isótipo, P; fotos do tipo, P640267!). 

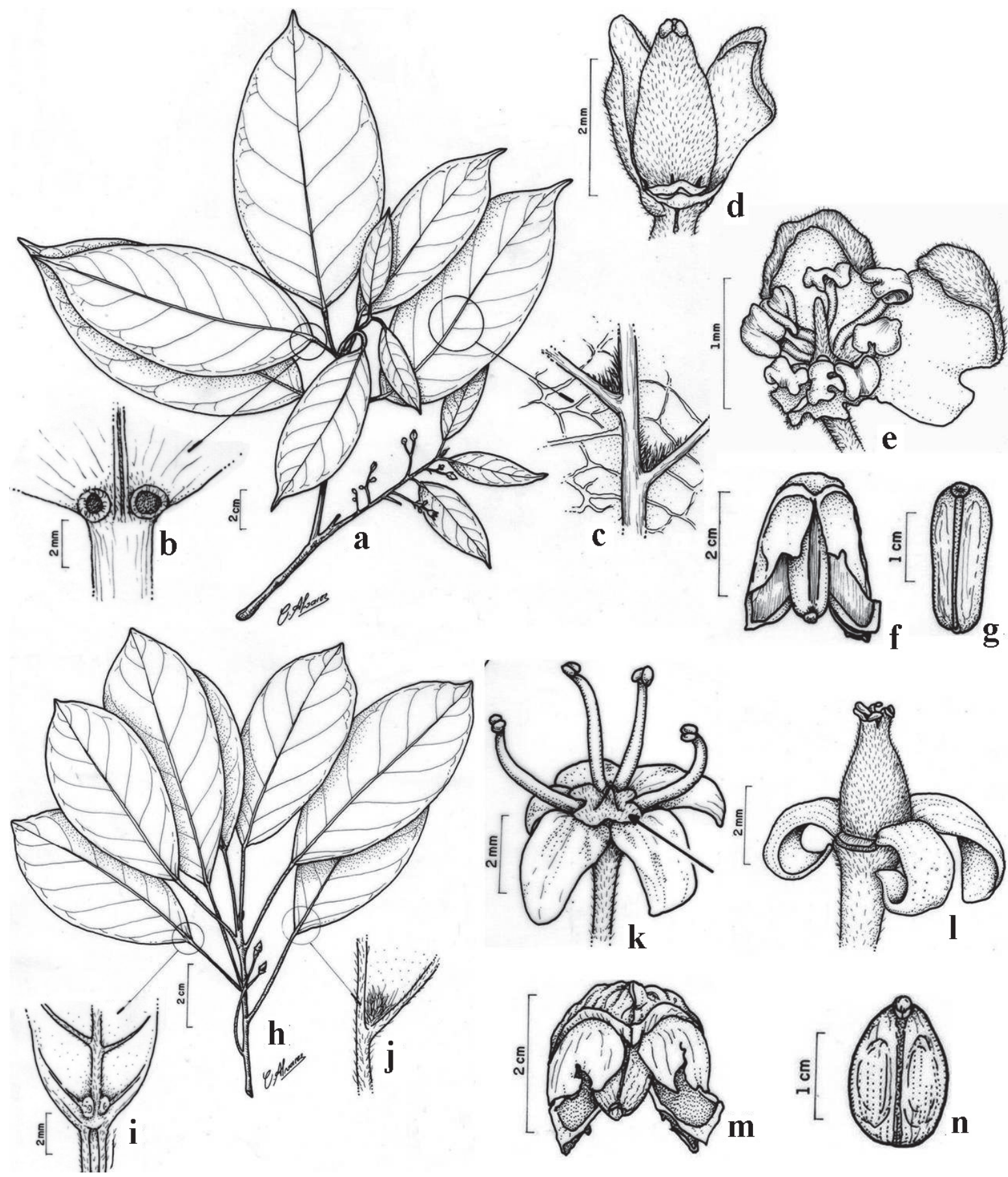

Figura 3. a-g. Micrandra rossiana R.E. Schult. a. Ramo com inflorescência. b. Glândulas basilaminares na face adaxial do limbo. c. Tufos de tricomas simples na face abaxial do limbo. d. Flor pistilada com disco basal anelar e estaminódios. e. Flor estaminada com pistilódio. f. Mericarpo com semente. g. Semente carunculada (a-c: H.C. Lima et al. 3335; d-e: P.S. Texeira 93; f-g: G.T. Prance et al. 4556). h-n. Micrandra siphonioides Benth. h. Ramo com inflorescência. i. Glândulas basilaminares na face adaxial do limbo. j. Tufo de tricomas na face abaxial do limbo. k. Flor estaminada, um estame retirado, mostrando pistilódio (seta). 1. Flor pistilada com disco anelar. m. Mericarpo com semente. n. Semente carunculada (h-1: J.R. Nascimento 554; m-n: P.J.S. Sousa 2).

Figure 3. a-g. Micrandra rossiana R.E. Schult. a. Branch with inflorescence. b. Basilaminar glands on adaxial leaf surface. c. Tufts of simple trichomes on abaxial leaf surface. d. Pistillate flower with basal annular disc and staminodes. e. Staminate flower with pistillode. f. Mericarp with seed. g. Carunculate seed (a-c: H.C. de Lima et al. 3335; d-e: P.S. Texeira 93; f-g: G.T. Prance et al. 4556). h-n. Micrandra siphonioides Benth. h. Branch with flowers. i. Basilaminar glands on the adaxial leaf surface. $\mathrm{j}$. Tuft of simple trichomes on the abaxial leaf surface. $\mathrm{k}$. Staminate flower, a stamen removed, with pistillode (arrow). 1. Pistillate flower with annular disc. m. Mericarp with seed. n. Carunculate seed (h-1: J.R. Nascimento 554; m-n: P.J.S. Sousa 2). 
$\equiv$ Micrandra siphonioides var. major (Baill.) Müll. Arg., Prodr. (15) 2: 709. 1866. Tipo. BRASIL. PARÁ: s.l., s.d., fl., Jerreira s.n. (isótipo, P; fotos do tipo, P!). $\equiv$ Micrandra siphonioides var. genuina Müll.Arg., Prodr. (15) 2: 710. 1866. Tipo. BRASIL. AmazonAs: rio Uaupés, 1852-1853, (fl.), Spruce 2427 (isótipos, P, TCD, GH!; fotos do tipo, P!, TCD!, GH!, GOET!, $\mathrm{K}$ !, E!).

$\equiv$ Micrandra heterophylla Poiss., Bull. Mus. Hist. Nat. (Paris) 8: 561. 1902. VENEZUELA. Haut Orénoque, X-1901, fl., fr., G. Lebeuf A. s.n., nom. nud.

$\equiv$ Micrandra lopezii var. microcarpa R.E. Schultes, Bot. Mus. Leafl. 27(3-4): 104. 1979. Tipo. BRASIL. AmazonAs: rio Aiary Jabarú, Içana, 8-XI-1947, fl., fr., R.L. Fróes 21364 (holótipo, IAN!), syn. nov.

Figura 3h-n

Árvore 8-30 m alt., $15-50 \mathrm{~cm}$ diâm. Ramos glabros. Folhas com nervação broquidódroma, concolores, 5,5-8 × 3-4 cm, elíptico-obovadas, membranáceas a cartáceas, margem inteira a levemente ondulada, plana, esparsamente pubescente, base obtusa, ápice acuminado; face adaxial raro pubescente sobre as nervuras principal e secundárias, restantes do limbo glabro, glândulas diminutas na junção da nervura principal com as secundárias, nervuras pouco proeminentes, par de glândulas basilaminares planas, ca. $1 \mathrm{~mm}$ diâm., enegrecido no centro; face abaxial com tufos de tricomas simples na junção da nervura principal com as secundárias, nervuras proeminentes, tricomas estrigosos, esparsos, ferrugíneos, restante glabro; pecíolo 2-3 cm compr., canaliculado, pubescente, incano, estípulas laterais 2 , caducas. Inflorescência panícula 6-10 cm compr., bissexuada, axilar, pluriflora, laxa, pedúnculo $3-5 \mathrm{~cm}$ compr., pubescente, bráctea ca. 1,2 mm compr., caduca, lanceolada, externamente pubescente, internamente glabra. Flores estaminadas com pedicelo 6-9 mm compr., pubescente; cálice 2-3 mm compr., 5-lobado, lobos concrescidos na base, elípticooblongos, retrorsos, externamente pubescentes, internamente glabros, glandulosos a papilosos; estames 5-6, homodínamos, 3-4 mm compr., filetes raro pubescentes, alternissépalos, disco basal pentalobado, pubescente, anteras basifixas, pistilódio presente, ca. $1 \mathrm{~mm}$ compr., cônico, densamente piloso. Flores pistiladas com pedicelo 3-4 mm compr., pubescente; cálice 4-5 × 2-3 mm, 5-lobado, lobos concrescidos na base, elíptico-oblongos, externamente pubescentes, internamente glabros, glandulosos a papilosos; ovário ca. $2 \mathrm{~mm}$, cônico, hirsuto, lobulado, disco basal anelado, pubescente; estiletes 3, curtos, ca. 0,5 mm compr., tubular, estigma bífido, glabro, estaminódios ausentes. Fruto 2,5-2,8 $\times$ ca. $3 \mathrm{~cm}$, mericarpos corrugados, pilosos, mesocarpo fibroso a seríceo, pedúnculo 3,5-3,9 cm compr. Sementes 1,3-15 × 1-1,3 cm, lisas, beges, obovoides, rafe proeminente, conspícua, enegrecida, carunculadas.

Ocorre na Colômbia (Tropicos 2010), Venezuela, Guiana (Funk et al. 2007), Peru e Brasil (AM, PA, RR). Distribuição restrita a Amazônia, podendo ser encontrada em floresta de terra firme de solo úmido, arenoso ou argiloso, campinarana, igapó, mata de várzea, restinga e margem de rios ou igarapés. Floresce entre julho e dezembro e frutifica entre janeiro e maio. As amostras de $M$. siphonioides do Peru, próximo aos rios Yavita e Nanay, e na Colômbia no rio Vaupés, ocorrem em vegetação sazonalmente inundada, revelando que esta espécie também apresenta adaptação para tal ambiente. Nomes Vulgares: Brasil. Amazonas. rio Uaupés: "arara-seringa"; rio Solimões: "cauchorana" e "seringarana"; rio Negro: "seringá-irarí"; Roraima: "momofi". Colômbia. rio Uaupés: "arara-seringa"; rio Miritiparaná: "ka-ro-a" (Yukuna), "ma-poó-a" (Tanimuka), "ö-bai-meko" (seringa de la sabola) (Miriña); rio Popeyacá: “ma-há-wö-he" ("semente de arara”) (Makuna). Venezuela. Território Federal: "caucho de guaco", "caucho de invierno"; rio Orinoco: "caucho kunudi" (Maquiretare); rio Caurá: "caucho tomoro". Peru. rio Amazonas: "seringarana” (Waika) (Schultes 1979).

Material selecionado. BRASIL. AmAPÁ: Quadrícula SA-22-VB, arredores do acampamento Ariramba, 27-VI-1982, fl., N.A. Rosa. 4433 (INPA). AmAzonAs: Reserva Ducke, Manaus-Itacoatiara, área do Acará, km 26, 02 $53^{\circ} \mathrm{S} 59^{\circ} 58^{\prime} \mathrm{W}, 28-\mathrm{VII}-1994$, fl., J.R. Nascimento \& E.C. Pereira 554 (IAN, INPA, MO, RB, R). PARÁ: rio Tapajós, 22-VII a 23-VIII-1929, fl., A. Ducke s.n. (RB 17894); São Luiz, rio Tapajós, IX-1944, (fr.), R.L. Fróes 20297 (IAN); BELÉM: seringal do Baldwin, Embrapa, ao lado do setor de produção de mudas, P.J.S. Souza 2 (IAN, MG). RoRAIMA: rio Uraricoera, cachoeira Tocuxema, 6345'W, 9-III-1979, (fr.), J.M. Pires 16903 (MG, RB). PERU. Departamento San Martín, Província Mariscal Cáceres, Distrito Catache Nuevo, 18-IV-1970, (fr.), J. Schunke V. 3937 (IAN). VENEZUELA. AMAZONAS: rio Negro, at base of Piedra del Cocuy, 8-V-1948, (fl.), F. López 9880 (IAN, R). Bolívar: below base along rio Tirica to mouth rio Torono, 09//III/1965, (fl.), J.A. Steyermark \& J.J. Wurdack 1298 (VEN). 
Micrandra siphonioides assemelha-se morfologicamente a $M$. minor por apresentar folhas elípticoobovadas, inflorescências paniculadas, laxas, flores estaminadas com cinco estames, alternissépalos, disco pentalobado, com centro densamente pubescente com tricomas simples e flores pistiladas com ovário hirsuto, lobulado e estilete trífido. Entretanto, separam-se devido $M$. siphonioides apresentar folhas com tufos de tricomas simples na junção das nervuras principal com as secundárias na face abaxial, glândulas inconspícuas na junção das nervuras principal com as secundárias na face adaxial, pistilódio nas flores estaminadas, e flores pistiladas com estilete curto, tubular, com estigma bífido.

$\mathrm{Na}$ análise dos materiais observaram-se variações quanto à presença e ausência de tufos de tricomas na face abaxial das folhas de $M$. siphonioides, considerados por Bentham (1854) e Schultes (1978) como um dos caracteres marcantes para separação desta espécie de $M$. minor; porém, a ausência desse caráter não constitui semelhanças entres essas espécies.

Schultes (1979) estabeleceu Micrandra lopezii var. microcarpa, com base em amostra com fruto de $20 \mathrm{~mm}$ compr. e a base da folha subcuneada, o que a diferencia de $M$. lopezii. A falta de ilustração e a diagnose incompleta dificultaram reconhecer a validade deste táxon. O holótipo, depositado no herbário IAN, possui apenas o fruto e as folhas (elípticas a obovadas), sendo que o número de nervuras secundárias e a presença de glândulas basilaminares planas indicam nítidas diferenças em relação à M. lopezii e semelhança com M. siphonioides. Sendo assim, aqui é proposta a sinonimização de Micrandra lopezii var. microcarpa em M. siphonioides.

8. Micrandra spruceana (Baill.) R.E. Schult., Bot. Mus. Leafl. 15(8): 217. 1952.

三Cunuria spruceana Baill., Adansonia 4: 288. 1864. Tipo. VENEZUELA. ad flumen Casiquiari, Vasiva et Pacimoni, 1853-1854, fl., Spruce 3299 (holótipo, G-DC; fotos do tipo, K!, GH!, G-DC!).

三 Micrandra cunuri Baill. ex Müll.Arg., Prod. 15(2): 1123. 1866, nom. nud.

$\equiv$ Pogonophora cunuri Baill. ex Müll.Arg., Prod. 15(2): 1124. 1866, nom. nud.

$\equiv$ Cunuria bracteosa Ducke, Notizbl. Bot. Gart. Berlin-Dahlen 11:586. 1932, nom. nud.

$\equiv$ Cunuria spruceana var. bracteosa (Ducke) R.E. Schultes ex Baldwin \& Schultes, Bot. Mus. Leafl. 12(10): 345. 1947. Tipo. BRASIL. Amazonas: rio Solimões, São Paulo de Olivença, 20-VIII-1929, fl., Ducke 23519 (Parátipo, RB!). $\equiv$ Cunuria australis R.E. Schult., Bot. Mus. Leafl. 12(10): 333-335. 1947. Tipo. BRASIL. Amazonas: Humaitá, on plateau between rio Livramento and rio Ipixuna, 7-18-XI-1934, fl., fr., B.A. Krukoff 7201 (isótipo, RB!; fotos do tipo, F!, A!, U!, MO!, NY!). $\equiv$ Cunuria glabra R.E. Schult., Mus. Bot. Leafl. 12(10): 339-340. 1947. Tipo. SURINAME. TAFELBERG: (Table Mountain), north of Savana II, 10-VIII-1944, fl., B. Maquire 24279 (holótipo, A!; fotos do tipo, A!, U!, BM!, GH!, US!).

$\equiv$ Micrandra australis (R.E. Schult.) R.E. Schultes, Bot. Mus. Leafl. 15(8): 202-203. 1952. Tipo. BRASIL. Amazonas: Humaitá, on plateau between rio Livramento and rio Ipixuna, 7-18-XI-1934, fl., fr., B.A. Krukoff 7201 (isótipo, RB!; fotos do tipo, F!, A!, $\mathrm{U}$ !, MO!, NY!), syn. nov.

$\equiv$ Micrandra glabra (R.E. Schult.) R.E. Schultes, Bot. Mus. Leafl. 15(8): 203. 1952. Tipo. SURINAME. TAFELBerg: Table Mountain, north of Savana II, 10-VIII-1944, (fl.), B. Maguire 24279 (holótipo, A!; fotos do tipo, A!, U!, BM!, GH!, US!), syn. nov.

Figura $4 \mathrm{a}-\mathrm{f}$

Árvore ca. 15-45 m alt., 10-70 cm diâm. Ramos glabros, estriados, estípulas apicais 2, foliáceas, involucrais, caducas, oblongo-lanceoladas, enegrecidas no centro, bordas onduladas, avermelhadas. Folhas com nervação broquidódroma, concolores, 10-18,5 ×5,7-8,5 cm, elípticas a orbiculares, subcoriáceas a coriáceas, margem discretamente revoluta, base obtusa a cordada, ápice acuminado a arredondado; face adaxial glabra, lustrosa a opaca, glândulas baselaminares 2, pateliformes, proeminentes, 1-2 mm diâm.; face abaxial glabra, nervura principal pouco proeminente; pecíolo 2-3,7 cm compr., glabro, canaliculado, estriado, ápice crasso, escurecido. Inflorescência dicásio, 3-7 cm compr., bissexuado, axilar ou terminal, laxo, rígido, raque levemente canaliculada, pubescente, tricomas simples, flores agrupadas em raque articulada, 1-1,5 cm compr., 2-3 bractéolas involucrais, ovais, côncavas, persistentes. Flores estaminadas sésseis; cálice 2-3 mm compr., 5-lobado, lobos concrescidos além da metade, obovados, hirsutos externa e internamente, curtos; estames 8-10, heterodínamos, 1-1,5 mm compr., raro pubescentes, disco basal tênue, anteras basifixas, pistilódio partido, pubescente, ferrugíneo. Flores pistiladas geralmente terminais, sésseis, pubescentes; cálice 3-4 cm compr., 5-lobado, lobos concrescidos além da metade, ovais, pubescentes externa e internamente; ovário ca. 2,5 mm compr., 

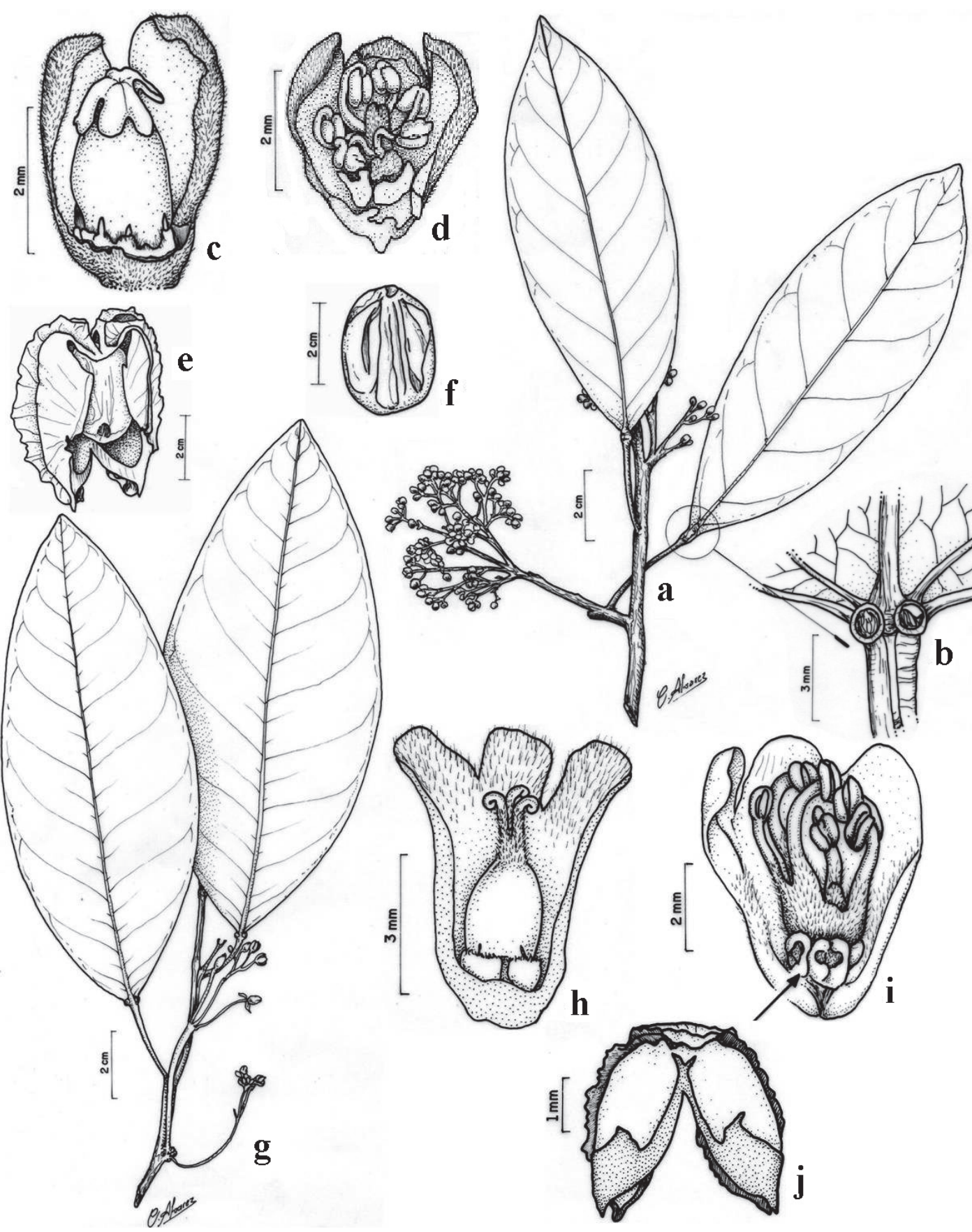

Figura 4. a-f. Micrandra spruceana (Baill.) R.E. Schult. a. Ramo com inflorescência. b. Glândulas basilaminares pateliformes na face adaxial do limbo. c. Flor pistilada com disco basal e os estaminódios. d. Flor estaminada com disco cupular lobado e pistilódio. e. Mericarpo com semente. f. Semente sem carúncula (a-d: J.E.L.S. Ribeiro 1625; e-f: G.T. Prance 10065). g-j. Micrandra sprucei (Müll. Arg.) R. E. Schult. g. Ramo com inflorescência em dicásio. h. Flor pistilada com disco basal e estaminódios. i. Flor estaminada com disco basal lobado e pistilódio (seta). j. Mericarpo com semente (g-i: Stropp, J. \& Assunção, P.A.C.L. s.n., INPA 234233; j: J.S. Rodrigues et al. 122).

Figure 4. a-f. Micrandra spruceana (Baill.) R.E. Schult. a. Branch with inflorescence. b. Basilaminar patelliform glands on adaxial leaf surface. c. Pistillate flower with basal disk and staminodes. d. Staminate flower with cupular lobed disc and pistillode. e. Mericarp with seed. f. Ecarunculate seed (a-d: J.E.L.S. Ribeiro 1625; e-f: G.T. Prance 10065). g-j. Micrandra sprucei (Müll. Arg.) R. E. Schult. g. Branch with inflorescence. h. Pistillate flower, showing basal lobed disk and staminodes. i. Staminate flower with lobed basal disc and pistillode (arrow). j. Mericarp with seed (g-i: Stropp, J. \& Assunção, P.A.C.L. s.n., INPA 234233; j: J.S. Rodrigues et al. 122). 
glabro, tereto, abruptamente obtuso no ápice, disco basal anelar, pubescente, estilete séssil, estigma 3, rotados, bipartidos, foliáceos, estaminódios 3-4 mm compr., crassos. Fruto 3-4 × 2,6-3,2 cm, mericarpos corrugados, glabros, mesocarpo fibroso, pedúnculo 3-4 cm compr. Sementes 2,7-3 × 2,1-2,5 cm, lisas, beges a marrons, ovais a oblongas, rafe proeminente, sem carúncula.

Ocorre na Colômbia (Tropicos 2010), Venezuela, Guiana, Suriname, Peru e Brasil (AC, AM, AP, PA, RR, MT). Amplamente distribuída e adaptada ao bioma Amazônico, sendo que dois novos registros foram detectados para os Estados do Acre (C.A.C Ferreira 10080 ) e Mato-Grosso (R.L. Fróes 20300). Floresce entre dezembro e março, e frutifica entre agosto e setembro. Nomes vulgares: Colômbia. Amazonas: "cunurí"; rio Caquetá: "ko-no-ko" (Miraña); rio Piraparaná: “peñ” (Makú), “wa-hö” (Makuna); rio Uaupés: "wah-puch'” (Tukano); rio Miritiparaná: "yé-cha" (Yukuna), "wan-hoo'-a-ma-ka-na" (Tanimuka); rio Guainía: "yé-ka” (Kuripako). Peru. Pebas: "conoco" (Witotos e Boros). Brasil. Amazonas: "cunurí" (Schultes, 1979). Roraima: "momofi" (Uaicá). Peru. Loreto: "shiringa masha".

Material selecionado: BRASIL. ACre: Município de Mâncio Lima, alto rio Moa, serra do Divisor, $73^{\circ} 38^{\prime} \mathrm{W}, 7^{\circ} 25^{\prime} \mathrm{S}, 15-\mathrm{X}-1989$, fr., C.A.C. Ferreira 10086 (INPA). AMAPÁ: contagem entre Porto Platon e Serra do Navio, 10-X a 15-XII-1976, (est.), N.A. Rosa 1320 (MG). Amazonas: Reserva Ducke, Manaus-Itacoatiara km 26, igarapé do Acará, $02^{\circ} 53$ 'S 59 58'W, 30-IV-1995, fl., J.E.L.S. Ribeiro et al. 1625 (INPA, MG, IAN, RB); rio Negro, Porto Curucuí, São Gabriel, est., R.L. Fróes 21129 (parátipo, IAC). Mato-Grosso: Tapajós, 16-X-1944, fr., R.L. Fróes 20300 (IAN). PARÁ: Vila Nova, rio Tapajós, abaixo da cachoeira Chacorão, 23-XII-1951, fl., fr., J.M. Pires 3606 (IAN). RoRAIMA: serra dos Surucucus, $2^{\circ} 42-47^{\prime} \mathrm{N}$, 633-36'W, 18-II-1969, fl., G.T. Prance et al. 10065 (INPA, MG, MO, NY). VENEZUELA. AMAZONAS: San Carlos de rio Negro, $1^{\circ} 56^{\prime} \mathrm{N}, 67^{\circ} 03^{\prime} \mathrm{W}, 19-\mathrm{V}-1981$, fr., E. Medina s.n (INPA 205282). PERU. LORETO: rio Tahuayo, Qda. Valentin, 11-I-1962, fl., A.A.V. Muestra 21 (SP). GUIANA. Região de MazaruniPotaro, 542'N; 6003'W, 12-VI-1986, fl., J.J. Poly \& K. Alfred 7658 (INPA).

Micrandra spruceana tem semelhança morfológica com M. rossiana e M. sprucei por apresentarem, principalmente, flores com lobos do cálice concrescidos além da metade das sépalas e estaminódios nas flores pistiladas. Entretanto, M. spruceana separa-se das duas por apresentar flores estaminadas com variação de 8-10 estames, pistilódio partido, flores pistiladas com estilete séssil, estigmas 3, rotados e ramos foliáceos. Micrandra spruceana exibe polimorfismo foliar acentuado, revelando formas bem variáveis desde elípticas, oblongas a orbiculares, além da presença de um par de estípulas involucrais na terminação dos ramos.

Berry (in Webster 1999), ao propor uma sinopse de Micrandra da Venezuela-Guayana (sete spp.), considerou M. glabra como válida. Entretanto, ao analisar o material completo, inclusive com a flor pistilada, verificou-se que as características de M. glabra são semelhantes às de M. spruceana, descrita anteriormente. O estilete séssil, estigma rotado, disco basal anelar, piloso e estames rudimentares em $M$. glabra, bem como a presença de glândulas basilaminares pateliformes, mericarpos glabros e sementes sem carúnculas em $M$. australis são características comumente encontradas em M. spruceana, daí ter-se considerado as duas espécies como sinônimos de M. spruceana.

9. Micrandra sprucei (Müll.Arg.) R.E. Schult., Bot. Mus. Leafl. 15(8): 218. 1952.

$\equiv$ Clusiophyllum sprucei Müll.Arg., Flora 47: 518. 1864. Tipo. VENEZUELA. rio Negro, San Carlos, 1853-1854, fl., fr., Spruce 3029 (holótipo, K; isótipos, P, GH, BR; fotos do tipo, P!, K!, BR!, F!).

三Cunuria crassipes Müll.Arg., Fl. Bras. 11(2): 510. 1874. Tipo. VENEZUELA. rio Negro, San Carlos, 1853-1854, (fl., fr.), Spruce 3474 (lectótipo, GH, designado por Baldwin \& Schultes (1947); isolectótipos, P, GH; fotos do tipo, P!, K!, BR!, F!). Figura 4g-j

Árvore 3-27 m alt., 12-25 cm diâm. Ramos levemente estriados, raramente esparso-pubescentes. Folhas com nervação craspedódroma, concolores, 11-14 × 6-7 cm, elípticas a obovadas, coriáceas, margem revoluta, base obtusa a retusa, ápice obtuso; face adaxial glabra, nervura principal proeminente, nervuras secundárias planas, uniformes, abruptamente curvas, glândulas basilaminares 2, pateliformes, 1-1,5 mm diâm.; face abaxial glabra, nervura principal proeminente, nervuras secundárias levemente proeminentes; pecíolo 1,5-2 cm compr., crasso, canaliculado, levemente estriado, ápice esparsopubescente, híspido. Inflorescência dicásio, $8-16 \mathrm{~cm}$ compr., bissexuado, axilar, pedúnculo 3-5 $\mathrm{cm}$ compr., canaliculado, esparso-pubescente, raque $1-2 \mathrm{~cm}$ 
compr., bractéolas 2-3 em cada flor, foliáceas, 3-4,5 cm compr., ovais a oblongas, uninérveas, caducas, borda pubescente. Flores estaminadas subsésseis; cálice 6-7 mm compr., 5-lobado, lobos concrescidos além da metade, eretos, obtusos, externamente pubescentes na base e ápice, internamente pubescentes; estames 5-7, homodínamos, 1,7-2 cm compr., metade basal pubescente, disco basal lobado, glandular, enrugado quando seco, carnoso, anteras dorsifixas, glabras, pistilódio ca. 0,5 mm compr., cônico, pubescente. Flores pistiladas subsésseis; cálice 6-7 mm compr., 5-lobado, lobos concrescidos além da metade, obtusos, eretos, externamente pubescentes na metade das sépalas, internamente pubescentes; ovário piriforme a ovóide, glabro, disco lobado, cupular, pubescente, estaminódio 1 em cada lobo, filiforme; estilete trífido, livre, hirsuto, ramos retrorsos, glabros. Fruto 2,8-3 $\times 3-3,3 \mathrm{~cm}$, mericarpos corrugados com pintas avermelhadas, glabros, mesocarpo fibroso. Sementes sem carúncula.

Ocorre na Colômbia, Venezuela, Guiana e Brasil (AM). Foi citada pela primeira vez para a Guiana na "Checklist of the Plants of the Guiana" (2007), com base em material coletado por H.D. Clarke et al. 9718, na região do rio Potaro. Endêmica do bioma Amazônico de grandes altitudes, encontrada em floresta densa, borda de rios e caatinga amazônica. Floresce entre março e dezembro, e frutifica entre abril e novembro. Nomes Vulgares: Colômbia. rio Uaupés: "uah-sô-nê-nê" (Tukano), "was-só-roo-re" (Gwanano). Brasil. Amazonas: "cunurí da caatinga" (Schultes, 1979), "nawé-né".

Material selecionado. BRASIL. Amazonas: rio Uaupés, Taraquá, 9-XI-1947, fl., J.M. Pires 946 (IAN); rio Uaupés, opposite Ilha das flores, 28-09-I-II-1948, fl., R.E. Schultes \& F. López 9658 (IAN, RB). COLÔMBIA. VAupés: rio Negro, San Felipe (E1 Castillo), below confluence of rios Guainia and Casiquiare, 12-XII-1947, fl., R.E. Schultes \& F. López 9320 (IAN). GUIANA. Pakaraima Mts., Aymatoi (sandstone), $5^{\circ} 55^{\prime} \mathrm{N}, 61^{\circ} \mathrm{W}, 17-\mathrm{X}-1981$, fr., P.J.M. Maas et al. 5828 (MG). VENEZUELA. SAN CARLOS: rio Negro, 9-XII-1947, fl., R.E. Schultes \& F. López 9284 (IAN, MO, P); rio Guainia, 1-VII-1959, fl., J.J. Wurdack \& L.S. Adderley 43267 (MO, RB).

Micrandra sprucei assemelha-se morfologicamente com M. spruceana por ambas possuírem folhas com um par de glândulas basilaminares, pateliformes, inflorescências dicásio, flores agrupadas na raque, lobos do cálice concrescidos além da metade e ovário glabro. Entretanto, M. sprucei diferencia-se por apresentar folhas com nervuras secundárias planas, craspedódromas, margem revoluta, inflorescência laxa, flores estaminadas com variação de 5-7 estames, flores pistiladas com estilete trífido, hirsuto, ramos retrorsos.

Nos estudos de Müller (1873) e Baldwin \& Schultes (1947) a espécie foi separada em chaves analíticas apenas pelo pecíolo crasso, curto, tamanho das cápsulas do fruto e folhas com nervações secundárias paralelas, apesar de serem fornecidas descrições e ilustrações das flores estaminadas e pistiladas. Neste trabalho são apresentadas novas informações sobre a morfologia da espécie, tais como: inflorescência dicásio e flores estaminadas com 5-7 estames.

\section{Agradecimentos}

Ao CNPq, pelas bolsas de Mestrado (Processo 133101/2010-0) e de Produtividade Científica (Processo 303424/2010-9), concedidas ao autor e co-autor, respectivamente; aos Curadores dos herbários mencionados pelas visitas, pelos empréstimos das coleções e envio de fotos; ao Programa de Pós-Graduação em Ciências Biológicas, pela estrutura necessária concedida a esta pesquisa; ao Dr. William L. Overal, do Museu Goeldi, pela confecção do Abstract e correção das Legendas em Inglês; aos colegas Carlos Alvarez e João Silveira, pelas ilustrações; ao colega Wanderson Silva, pelo auxílio na formatação das figuras; ao Dr. João Ubiratan M. dos Santos, pelas facilidades concedidas durante o Curso de Pós-Graduação; aos assessores de Hoehnea e às pesquisadoras Dra. Ana Cristina A. de Aguiar Dias e Dra. Margareth F. de Sales, pelas sugestões adicionadas ao manuscrito.

\section{Literatura citada}

APG II. 2003. An update of the angiosperm phylogeny group classification for the orders and families of flowering plants. Botanical Journal of the Linnean Society 141: 339-436.

Baldwin, J.T. \& Schultes, R.E. 1947. A conspectus of the genus Cunuria. Botanical Museum Leaflets, Harvard University 12: 345-359.

Bentham, G. 1854. On the north Brazilian Euphorbiaceae in the collections of Mr. Spruce. Hooker's Journal Botanical Kew Garden Miscellaneus 6: 321-333. 
Barroso, G.M., Morim, M.P., Peixoto, A.L. \& Ichaso, C.L.F. 1999. Frutos e sementes: morfologia aplicada à sistemática de dicotiledôneas. Viçosa, Editora da Universidade Federal de Viçosa, Viçosa.

Berry, P.E. \& Wiedenhoeft, A.C. 2004. Micrandra inundata (Euphorbiaceae), a new species with unusual wood anatomy from black-water river banks in southern Venezuela. Systematic Botany. 29: 125-133.

Cordeiro, I. \& Secco, R. 2013. Micrandra in Lista de Espécies da Flora do Brasil. Jardim Botânico do rio de Janeiro. Disponível em: http://floradobrasil.jbrj.gov.br/ jabot/floradobrasil/FB17617 (acesso em 26.III.2013).

Funk, V., Hollowell, T, Berry, P.E., Kelloff, C \& Alexander, S.N. 2007. Checklist of the Plants of the Guianas Shield (Venezuela: Amazonas, Bolivar, Delta Amacuro; Guyana, Surinan and French Guiana). Disponível em: http//:botany.si.edu/bdg/pdf/vol55web. pfd (acesso em 16.III.2010).

Jablonski, E. 1967. Euphorbiaceae. In: B. Maguire (ed.). Botany of the Guayana Highland, part. VII. Memoirs of the New York Botanical Garden 17: 80-190.

Lawrence, G.H.M. 1973. Taxonomy of Vascular Plants. Macmillan, New York.

Lanjouw, J. 1931. The Euphorbiaceae of Surinam. J. H. de Bussy, Amsterdam.

Lorenzi, H. 2008. Árvores brasileiras: manual de identificação e cultivo de plantas arbóreas do Brasil. 4 ed. Instituto Plantarum, Nova Odessa.

Müller, J. 1864. Neue Euphorbiaceen des herbarium Hooker in Kew. Flora 33: 513-528.

Müller, J. 1866. Euphobiaceae-Crotonae. In: A. De Candolle (ed). Prodomus Systematis naturalis Regni Vegetabilis. Pars.15, n.2. Masson, Paris, pp. 511-710.

Müller, J. 1873. Euphorbiaceae. In: C.P.F. Martius \& A.G. Eichler (eds.). Flora brasiliensis. v.11, n.2. Masson \& Filii, Paris, pp.1-292.

Nowicke, J.W. 1994. A palynological study of Crotonoideae (Euphorbiaceae). Annals of the Missouri Botanical Garden 81: 245-269.

Pax, F. 1910. Euphorbiaceae-Jatropheae. In: A. Engler. Das Pflanzenreich. IV. 147. v.42. Willhelm Engelmann, Leipzig, pp. 3-21.

Prance, G.T. 1988. Padrões de distribuição e especiação em Chrysobalanaceae e outras famílias de plantas amazônicas. Acta Botanica Brasilica 1: 1-25.

Radcliffe-Smith, A. 2001. Genera Euphorbiacearum. Royal Botanical Gardens, Kew.

Radford, A.E.,Dickson, W.C., Massey, J.R. \& Bell, C.R. 1974. Vascular Plants Systematics. Harper \& Row, New York.
Rizzini, C.T. 1977. Sistematização terminológica da folha. Rodriguésia 42: 103-125.

Schultes, R.E. 1945. Plantae Colombiana X: De Euphorbiaceae notae diversae. Caldasia 3: 247-249.

Schultes, R.E. 1952. Studies in the genus Micrandra I. The relationship of the genus Cunuria to Micrandra. Botanical Museum Leaflets, Harvard University 15: 201-221.

Schultes, R.E. 1968. The Amazon Indian and evolution in Hevea and related genera. Botanical Museum Leaflets, Harvard University 37: 123-152.

Schultes, R.E. 1977. Diversas plantas comestíveis nativas do noroeste da Amazônia. Acta Amazonica 5: 317-327.

Schultes, R.E. 1978. De Plantis Toxicariis e Mundo Novo Tropicale commentationes XXIII. Notes on biodynamic plants of aboriginal use in the northwestern Amazonia. Botanical Museum Leaflets, Harvard University 25: 185-186.

Schultes, R.E. 1979. Studies in the genus Micrandra II. Miscellaneous taxonomic and economic notes. Botanical Museum Leaflets, Harvard University 27: 93-111.

Secco, R.S. 2005. Flora da Reserva Ducke, Amazonas, Brasil. Euphorbiaceae - Parte I. Rodriguésia 56: 143-168.

Souza, V.C. \& Lorenzi, H. 2008. Botânica sistemática: guia ilustrado para identificação das famílias de fanerógamas nativas e exóticas do Brasil, baseado em APG II. 2 ed. Instituto Plantarum, Nova Odessa.

Spruce, R. 1908. Notes of a botanist on the Amazon and Andes. Macmilian, London.

Thiers, B. 2012. Index Herbarium. A global directory of hebaria and associated staff. New York Botanical Garden's Virtual Herbarium. Disponível em: http: sweetgum.nybg.org/ih/> (acesso em 05.III.2013).

Tropicos. Missouri Botanical Garden. Disponível em: http://www.tropicos.org/Name/12805951 (acesso em 25.III.2010).

Webster, G.L. 1994. Synopsis of the genera and suprageneric taxa of Euphorbiaceae. Annals of the Missouri Botanical Garden 81: 33-144.

Webster, G. L., Del-Arco-Aguilar, M. J. \& Smith, B. A. 1996. Systematic distribuition of foliar trichomes types in Croton (Euphorbiaceae). Botanical Journal of the Linnean Society 121: 41-57.

Webster, G.L., Berry, P.E., Armbruster, W.S., Esser, H.J., Gillespie, L.J. Hayden, W.J., Levin, G.A., Secco, R.S. \& Heald, S.V. 1999. Euphorbiaceae. In: P.E. Berry, K. Yatskievych, \& B.K. Holst (eds.). Flora of the Venezuelan Guayana. St. Louis, Missouri Botanical Garden, v. 5, pp.72-228. 


\section{Lista de exsicatas}

A. Ducke 1087 (8); A. Ducke 1298 (7); A. Ducke 146 (8); A. Ducke 1463(7); A. Ducke 1554 (8); A. Ducke 1589(7); A. Ducke 24873 (8); A. Ducke 5398 (1); A. Ducke 848 (8); A. Ducke RB 23514 (7); A. Ducke s.n. (7); A. Ducke s.n. RB 13512 (7); A. Ducke s.n. RB 17894 (7); A. Ducke s.n. RB 23519 (8); A. Ducke s.n. RB 35437 (8); AcevedoRdgz et al. 14716 (8); A. Rozza 215 (1); A. Daniel s.n. IAC 21966 (1); B. Stergios \& J. Velazco 14313 (6); B.A. Krukoff's 7201 (8); B.G.S. Ribeiro 884 (6); B.W. Nelson 901 (8); C.A. Cid \& J. Lima 3651 (7); C.A. Cid et al. 8508 (8); C.A. Cid Ferreira et al. 7253 (5); C.A. Sothers et al. 139 (7); C. Farney et al. 1834 (8); C.V. Castilho 450 (8); C.V. Castilho 455 (8); C.F.O. Santos s.n. SP292185 (1); D.A.L. Filho et al. 89 (7); D.C. Daly et al. 4445 (8); D. Coêlho 830 (5); D. Coelho 830 (6); Dr. Tahuchi s.n. INPA 7820 (9); E.C. Franco s.n. IAN50 (7); E.C. Pereira 62 (7); E. Oliveira 69 (8); E. Ferreira 57/2 (7); E. Oliveira 398 (1); E. Oliveira 505 (1); E. Oliveira 829 (1); E. Oliveira 837 (1); G. A. Aymard et al. 11291 (3); G.A. Black 48-2715 (9); G.M. Araújo 352 (1); G.M. Araújo 422 (1); G.M. Araújo 425 (1); G. Martinelli 14539 (7); G. Martinelli 14627 (7); G.S. Bunting et al. 7222 (1); G.T. Prance 13618 (8); G.T. Prance 16465 (8); G.T. Prance 22959 (8); G.T. Prance et al. 10556(6); G.T. Prance et al. 14310 (6); H.C. de Lima et al. 3335 (6); H.F. Leitão Fo. etal. 10105 (1); H.F. Leitão Fo. et al. 12477(1); H. Lorenzi 1497 (1); H. Lorenzi s.n. SP262197 (1); H.T. Beck et al. 1056 (6); I. Cordeiro 261 (7); I. Cordeiro et al. 842 (1); J.A. Steyermark \& J.J. Wurdack 1298 VEN101665 (6); J.A. Steyermark s.n VEN59686 (6); J.A. Steyermark s.n VEN63289 (6); J.A. Steyermark s.n VEN63290 (6); J.E.A. Bertoni \& A. Geremias 624 (1); J.E.L.S. Ribeiro et al. 2657(7); J.E.L.S. Ribeiro et al. 893 (7); J.L. Paixão et al. 4 (1); J. Lanjouw et J.C. Liedeman 2571 (1); J. Lanjouw et J.C. Lindeman 2735 (1); J.M. Pires 1011 (9); J.M. Pires 1055 (9); J.M. Pires 563 (8); J.M. Pires 6825 (1); J.M. Pires 6825 (1); J.M. Pires 7064 (1); J.M. Pires 840 (9); J.M. Pires 930 (8); J.M. Pires 971 (6); J.M. Pires 971 (8); J.M. Pires 982 (8); J.M. Pires 982 (9); J.M. Pires e L.R. Marinho 15776 (6); J.M. Pires e L.R. Marinho 15940 (8); J.M. Pires et al. 5268 (IAN) (1); J.M. Pires et N.T. Silva 4604 (1); J.M. Poole 1918 (8); J.M. Pires 827 (7); J. Ramos 452 (5); J. Ribeiro 10 (6); J. Ribeiro 31 (6); J.S. Rodrigues 122 (9); J. Stropp \& P.A.C.L. Assunção s.n INPA234233 (9); J.M. Poole 2099 (7); J. Schunke V. 3612 (7); K. Kubitzki 88-119 (5); K. Kubitzki et al. 79-226 (5); L. Coêlho et al. 387 (5); L. Coelho et al. 403 (6); L. Delgado 395 (6); L.G. Lohmann et al. 6 (7); L. Rodriguez et al. 279 (6); L. Rodriguez et al. 302 (6); L. Rodriguez et al. 356 (6); L. Rodriguez et al. 391 (6); L. Salas TT-137 (6); M. Alves et al. 2343 (7); M. Barbosa
1692 (6); M. Freitas \& D. Coêlho 17 (8); M.G. Van Roosmalen 1541 et al. (7); M.R. Cordeiro 299 (8); M.R. Cordeiro 339 (8); M.R. Cordeiro MC-4-34 (1); N.A. Rosa 400 (6); N.A. Rosa e L. Coelho 571 (6); N.T. Silva 3822 (6); N.T. Silva 3839 (9); N.T. Silva 4363 (6); O.C. Nascimento et al. 18 (8); O. Kotchtkoff-Henriques \& M. Oliveira (2) 391 (1); P. Cavalcante 675 (9); P.E. Berry et al. 5681 (3); P.E. Berry et al. 6066 (3); P.J.S. Souza 1 (5); P.J.S. Souza 2 (7); P. Fiaschi e A.V. Christianini 375 (1); P.S. Teixeira 50 (6); P.S. Teixeira 63 (6); P.S. Teixeira 27 (5); P.S. Teixeira 35 (6); P.S. Teixeira 78 (5); P.S. Teixeira 15 (6); P.S. Texeira 93 (6); R. E. Schultes 9043 (8); R.E. Schultes \& F. López 9358 (9); R.E. Schultes 1 (8); R.E. Schultes 10221 (8); R.E. Schultes 10222 (8); R.E. Schultes 2 (9); R.E. Schultes 24510 (5); R.E. Schultes 3 (9); R.E. Schultes 8860 (8); R.E. Schultes 8984 (9); R.E. Schultes 9024 (9); R.E. Schultes 9044 (9); R.E. Schultes 9153 (4); R.E. Schultes 9222 (9); R.E. Schultes 9338 (9); R.E. Schultes 9343A (8); R.E. Schultes 9368 (8); R.E. Schultes 9373 (9); R.E. Schultes 9375 (9); R.E. Schultes 9380 (8); R.E. Schultes 9454 (8); R.E. Schultes 9456 (9); R.E. Schultes 9464 (IAN); R.E. Schultes 9541 (8); R.E. Schultes 9625 (7); R.E. Schultes 9644-c (9); R.E. Schultes 9668 (9); R.E. Schultes et F. López 9266 (8); R.E. Schultes et F. López 9294 (8); R.E. Schultes et F. López 9295 (9); R.E. Schultes et F. López 9324 (8); R.E. Schultes et F. López 9354 (9); R.E. Schultes et Francisco Lópes 8767 (8); R.E. Schultes et Francisco Lópes 8791-A (8); R.E. Schultes et Francisco López 10181 (9); R.E. Schultes et Francisco López 8942 (8); R.E. Schultes et Francisco López 9674 (9); R.E. Schultes et J.M. Pires 9026(8); R.E. Schultes et J.M. Pires 9062 (8); R. Evans et al. 2349 (1); $R$. Evans et al. 2465 (1); R. Evans et al. 2646 (1); R.L. Fróes 20697 (8); R.L Fróes 34794 (8); R.L. Fróes 20505 (8); R.L. Fróes 20752 (8); R.L. Fróes 20897 (7); R.L. Fróes 21003 (5); R.L. Fróes 21396 (9); R.L. Fróes 21477 (7); R.L. Fróes 21677 (6); R.L. Fróes 22152 (8); R.L. Fróes 22242 (8); R.L. Fróes 22647 (7); R.L. Fróes 22697 (7); R.L. Fróes 22700 (7); R.L. Fróes 23306 (7); R.L. Fróes 25238 (8); R.L. Fróes 28246 (9); R.E. Schultes 9057 (9); R.L. Fróes 28758 (9); R.L. Fróes 33191 (8); R.L. Fróes et G. Addison 28605 (9); R.L. Fróes et G. Addison 28605 (9); R.L. Fróes et G. Addison 28621 (8); R.L. Fróes et G. Addison 28640 (8); R.L. Fróes et G. Addison 28563 (5); R. Spruce 2427 (7); R. Spruce 2479 (5); Rodrigues 1030 (9); Rodrigues 818 (9); Steven R. Hill 13102 (1); Van Enden 9 (1); W.A. Rodrigues 10856 (9); W. Fox s.n MG 11851 (5); W. Rodrigues 580 (8); W. Rodrigues 6083 (7); W. Rodrigues 8677 (6); W. Rodrigues 8959 (6); W. Rodrigues 8970 (6); W. Rodrigues 8993 (1); W. Rodrigues 9587 (6); W. Rodrigues 9861 (7); $W$. Rodrigues 9864 (1). 